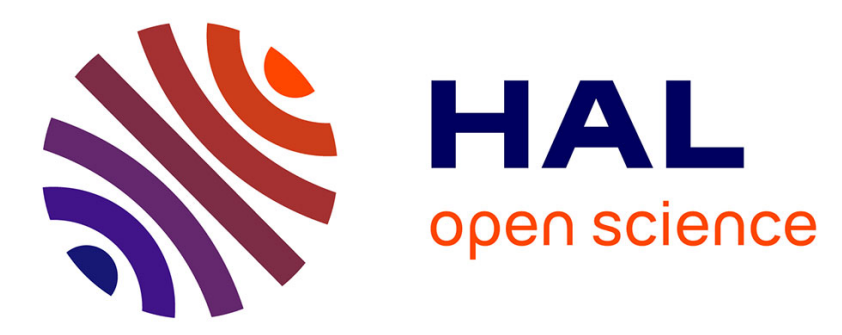

\title{
Cryogenic Photochemical Synthesis and Electronic Spectroscopy of Cyanotetracetylene
}

Urszula Szczepaniak, Robert Kolos, Marcin Gronowski, Michèle Chevalier, Jean-Claude Guillemin, Michal Turowski, Thomas Custer, Claudine Crépin

\section{- To cite this version:}

Urszula Szczepaniak, Robert Kolos, Marcin Gronowski, Michèle Chevalier, Jean-Claude Guillemin, et al.. Cryogenic Photochemical Synthesis and Electronic Spectroscopy of Cyanotetracetylene. Journal of Physical Chemistry A, 2017, 121 (39), pp.7374-7384. 10.1021/acs.jpca.7b07849 . hal-01617947

\section{HAL Id: hal-01617947 \\ https://hal-univ-rennes1.archives-ouvertes.fr/hal-01617947}

Submitted on 24 Oct 2017

HAL is a multi-disciplinary open access archive for the deposit and dissemination of scientific research documents, whether they are published or not. The documents may come from teaching and research institutions in France or abroad, or from public or private research centers.
L'archive ouverte pluridisciplinaire HAL, est destinée au dépôt et à la diffusion de documents scientifiques de niveau recherche, publiés ou non, émanant des établissements d'enseignement et de recherche français ou étrangers, des laboratoires publics ou privés. 


\section{Cryogenic Photochemical Synthesis and Electronic}

\section{Spectroscopy of Cyanotetracetylene}

Urszula Szczepaniak $^{a, b} *$, Robert Kołos ${ }^{b}$, Marcin Gronowski ${ }^{b}$, Michèle Chevalier ${ }^{a}$, Jean-Claude

Guillemin $^{c}$, Michat Turowski ${ }^{b,}+{ }^{\prime}$, Thomas Custer $^{b}$, and Claudine Crépin ${ }^{a}$

a Institut des Sciences Moléculaires d'Orsay (ISMO), CNRS, Univ. Paris-Sud, Université ParisSaclay, F-91405 Orsay, France,

b Institute of Physical Chemistry, Polish Academy of Sciences, Kasprzaka 44/52, 01-224 Warsaw, Poland,

c Institut des Sciences Chimiques de Rennes, École Nationale Supérieure de Chimie de Rennes, CNRS, UMR 6226, 11 Allée de Beaulieu, CS 50837, 35708 Rennes Cedex 7, France

*tel.+48223433353 ; e-mail :uszczepaniak@ichf.edu.pl,urszula.szczepaniak@u-psud.fr

Present addresses

$\uparrow$ University of Colorado at Boulder, Department of Chemistry and Biochemistry, 215 UCB, Boulder, CO 80309-0215 


\begin{abstract}
$\mathrm{HC}_{9} \mathrm{~N}$ is a molecule of astrochemical interest. In this study, it was produced in cryogenic $\mathrm{Ar}$ and $\mathrm{Kr}$ matrices from UV-photolyzed diacetylene/cyanodiacetylene mixtures. Its strong phosphorescence was discovered and served for the identification of the compound. Vibrationally-resolved phosphorescence excitation spectra gave insight into excited singlet electronic states. Two electronic systems were observed: around $26000-34000 \mathrm{~cm}^{-1}$ and $35000-50000 \mathrm{~cm}^{-1}$. Energies of the second excited singlet and the lowest triplet state were derived from analysis of these systems. Vibrational and electronic spectroscopic features were assigned with the assistance of density functional theory calculations. Some trends concerning the electronic spectroscopy of $\mathrm{HC}_{2 \mathrm{n}+1} \mathrm{~N}$ family molecules are presented.
\end{abstract}




\section{INTRODUCTION}

Monocyanopolyynes $\left(\mathrm{HC}_{2 n+1} \mathrm{~N}\right)$ constitute the most prominent homologous series of astrochemically-relevant molecules. They have been detected via microwave rotational transitions in many extraterrestrial sources up to $n=4$. Cyanoacetylene, $\mathrm{HC}_{3} \mathrm{~N}$, the smallest neutral molecule possessing both $-\mathrm{C} \equiv \mathrm{C}-$ and $-\mathrm{C} \equiv \mathrm{N}$ structural motifs, was first observed in a star-forming region Sagittarius $(\operatorname{Sgr} B 2(N))^{1}$ and then in other Galactic ${ }^{2-4}$ and extragalactic ${ }^{5}$ radio sources. It has also been detected in the atmosphere of $\operatorname{Titan}^{6,7}$ and in Hale-Bopp comet ${ }^{8}$. Along with cyanoacetylene, longer members of the $\mathrm{HC}_{2 n+1} \mathrm{~N}$ series $(n=2,3)$ have been found in several molecular clouds. ${ }^{9} \mathrm{HC}_{9} \mathrm{~N}$ (cyanotetraacetylene, 1-cyano-octa-1,3,5,7-tetrayne or nona2,4,6,8-tetraynenitrile) was first observed in 1978 at millimeter wavelengths in the dense interstellar cloud $\mathrm{HCl}-2 .^{10}$ It has also been found in expanding circumstellar envelopes (IRC $+10216^{11,12}$ and CRL $2688^{12}$ ). As observations of the $n=5$ species, $\mathrm{HC}_{11} \mathrm{~N}$, in IRC $+10216^{13}$ and in the Taurus Molecular Cloud ${ }^{14}$ have been challenged, first in IRC $+10216^{14}$ and now in TMC- $1,{ }^{15} \mathrm{HC}_{9} \mathrm{~N}$ is currently considered the longest member of the family to have been observed in space.

The astrochemical synthesis of monocyanopolyynes probably involves the reactions of $\mathrm{CN}^{\bullet}$ or $\mathrm{C}_{2 n+1} \mathrm{~N}^{\bullet}$ radicals with polyynic hydrocarbons $\mathrm{HC}_{2 m} \mathrm{H}$. Cherchneff et al. proposed the following pathway for formation of monocyanopolyynes around IRC $+10216: \mathrm{HC}_{2} \mathrm{H}+\mathrm{C}_{2 n+1} \mathrm{~N}^{\bullet} \rightarrow \mathrm{HC}_{2 n+3} \mathrm{~N}$ $+\mathrm{H}^{\bullet 16,17}$. Loomis et al. ${ }^{15}$ suggested that cyclization reactions are responsible for non-detection of $n>4$ cyanopolyynes.

The astronomical detections of $\mathrm{HC}_{9} \mathrm{~N}$ were based on microwave spectroscopy combined with quantum chemical studies of molecular structure. ${ }^{18-21}$ Density functional theory (B3LYP) investigations ${ }^{22}$ have suggested that $\mathrm{HC}_{2 n+1} \mathrm{~N}$ compounds should be linear and polyynic (having alternating single and triple bonds) at least up to $n=8$. Vichietti and Haiduke predicted IR spectra of long cyano- ${ }^{23}\left(\mathrm{HC}_{2 n} \mathrm{CN}\right)$ and isocyanopolyynes ${ }^{24}\left(\mathrm{HC}_{2 n} \mathrm{NC}\right)$ and suggest that the central triple bond stretching mode is the one producing the strongest band. 
Gas-phase spectroscopic studies of $\mathrm{HC}_{9} \mathrm{~N}$ are limited to microwave measurements in which minute amounts of the substance are transiently formed in a discharge plasma using acetylene with acrylonitrile ${ }^{25}$ or dicyanoacetylene with cyanoacetylene ${ }^{26}$ as seed gases. These investigations allowed derivation of the molecular geometry. Independently, electronic absorption and NMR spectra of $\mathrm{HC}_{9} \mathrm{~N}$ in organic solvents have been reported ${ }^{27-32}$. In particular, Wakabayashi et $a l .{ }^{31}$ obtained $\mathrm{HC}_{2 n+1} \mathrm{~N}(n=3-6)$ by laser ablation of isotope-enriched (99\% $\left.{ }^{13} \mathrm{C}\right)$ graphite in liquid acetonitrile followed by chromatographic purification. Very small amounts of the compound were then characterized by UV absorption and NMR spectroscopy. Isotopic experiments proved that the carbon atoms of $\mathrm{HC}_{9} \mathrm{~N}$ came both from graphite and solvent. The molecule has also appeared among the products of graphite bombardment with high energy $\mathrm{H}_{2}$ and $\mathrm{N}_{2}$ beams. ${ }^{33}$

In order to extend the spectroscopic characterization of cyanotetraacetylene, we aimed at synthesizing the molecule in noble gas matrices. Cryogenic photochemical syntheses of cyanopolyacetylenes have already been demonstrated for cyanodiacetylene $\left(\mathrm{HC}_{5} \mathrm{~N}\right)^{34,35}$ and cyanotriacetylene $\left(\mathrm{HC}_{7} \mathrm{~N}\right)^{36}$. Cyanodiacetylene appeared in solid $\mathrm{Ar}$ doped with $\mathrm{HC}_{3} \mathrm{~N} / \mathrm{C}_{2} \mathrm{H}_{2}$ mixtures $^{34}$ irradiated using a $\mathrm{H}_{2}$ discharge lamp emitting in the far-UV. It was also seen in Ar, $\mathrm{Kr}, \mathrm{N}_{2}$, and $\mathrm{pH}_{2}$ solids containing $\mathrm{HC}_{3} \mathrm{~N}$ alone and photolyzed at $193 \mathrm{~nm}$ using a laser. ${ }^{35}$ Cyanotriacetylene was detected in solid $\mathrm{Ar}$ doped with a mixture of either $\mathrm{HC}_{3} \mathrm{~N}$ and $\mathrm{C}_{4} \mathrm{H}_{2}$ (diacetylene) or $\mathrm{HC}_{5} \mathrm{~N}$ and $\mathrm{C}_{2} \mathrm{H}_{2},{ }^{36}$ and photolyzed either by excimer laser radiation or an $\mathrm{H}_{2}$ discharge lamp. The $\mathrm{HC}_{7} \mathrm{~N}$ molecule has also been produced by electric discharges in a mixture of $\mathrm{HC}_{3} \mathrm{~N}$ and $\mathrm{Kr}$ just prior to trapping on a cold window. ${ }^{37}$ In all of these cryogenic approaches, the cyanopolyacetylenes generated were found to emit strong phosphorescence which has proved to be the most sensitive spectroscopic indicator of their presence. Here we verified that a mixture of $\mathrm{C}_{4} \mathrm{H}_{2}$ and $\mathrm{HC}_{5} \mathrm{~N}$ precursors could couple to produce $\mathrm{HC}_{9} \mathrm{~N}$ during $\mathrm{UV}$-assisted, lowtemperature synthesis. The spectroscopic identification has been supported using density functional theory calculations of electronic and vibrational energy levels. 


\section{EXPERIMENT}

The precursor molecules were prepared using the methods developed by Trolez \& Guillemin ${ }^{38}$ $\left(\mathrm{HC}_{5} \mathrm{~N}\right)$ and Khlifi et al. ${ }^{39}\left(\mathrm{C}_{4} \mathrm{H}_{2}\right) . \mathrm{HC}_{5} \mathrm{~N}$ was alternately exposed to vacuum at $\mathrm{T}<200 \mathrm{~K}$ and then warmed to remove $\mathrm{CO}_{2}$ and other volatile impurities. This cycle was repeated until the rate of pressure rise during warming was negligible. $\mathrm{C}_{4} \mathrm{H}_{2}$ was subjected to several freeze-pump-thaw cycles $(T<200 \mathrm{~K}$, with some loss of the product). Purification of both precursors was carried out directly before the experiments.

Noble gases ( $\mathrm{Kr} 4.0$ or $\mathrm{Ar} 6.0$, Messer) were mixed with $\mathrm{C}_{4} \mathrm{H}_{2}$ and $\mathrm{HC}_{5} \mathrm{~N}$ at typical ratios of approx. 500:1:1 using standard manometric techniques. This mixture was subsequently trapped on a sapphire substrate window held at either $30 \mathrm{~K}(\mathrm{Kr})$ or at $22 \mathrm{~K}(\mathrm{Ar})$ as measured and regulated with a Scientific Instruments Inc. 9620-1 temperature controller. The closed-cycle helium refrigerator (Air Products Displex DE202FF) was equipped with external $\mathrm{CaF}_{2}$ windows. The typical amount of deposited gas was 6-8 mmol. Composition of the samples was verified with a Nicolet Nexus 670/870 FTIR spectrometer with a maximal resolution of $0.125 \mathrm{~cm}^{-1}$ and equipped with a liquid nitrogen-cooled MCT detector. Spectra consisted of 256 or 1024 averaged interferograms. To induce the photochemical transformations of precursor molecules, cryogenic matrices were irradiated with a $193 \mathrm{~nm}$ ArF excimer laser (Coherent Compex Pro), either during or after the sample deposition. The laser typically operated at a repetition rate of $10 \mathrm{~Hz}$ and the energy delivered to the sample surface did not exceed $5 \mathrm{~mJ} / \mathrm{cm}^{2}$ per pulse. While argon is the most commonly used rare gas in matrix experiments, krypton matrices were preferred here, as they have already been shown to supply strong and well resolved spectra of embedded cyanopolyacetylenes. ${ }^{35,37}$ Thermal processing, i.e. annealing, was accomplished by warming up to $\sim 30-40 \mathrm{~K}$ and then re-cooling (only for $\mathrm{Kr}$ ). The lowest temperature reached for the cryogenic samples was $7 \mathrm{~K}$.

The identification of photolysis products relied on selectively excited electronic luminescence. Two modes of measurement were employed. The first mode involved excitation at a fixed 
wavelength followed by recording the resulting dispersed phosphorescence spectrum. This spectrum contains information on vibrational frequencies in the ground electronic state of light emitting products. The second mode gave access to vibrations in an excited singlet state, and relied on scanning the excitation wavelengths while recording the phosphorescence signal. A Continuum Surelite II + OPO Horizon laser system operating in the 192-400 nm range was used for the excitation. The pulse repetition rate of this laser system was $10 \mathrm{~Hz}$. Phosphorescence was dispersed with a $0.6 \mathrm{~m}$ Jobin-Yvon grating monochromator and detected with a gated CCD camera (Andor iStar DH720) with a detection range of 380-800 $\mathrm{nm}$ and a resolution of approx. $0.04 \mathrm{~nm}$. Time synchronization between laser pulses and detection of phosphorescence was provided by a home-made triggering device.

Phosphorescence decay time measurements were performed using a photomultiplier (Hamamatsu H3177-50 PMT) with a detection range of $200-850 \mathrm{~nm}$ connected to the monochromator. Parallel to the phosphorescence intensity measurements, the excitation laser intensity was monitored with a photodiode.

\section{COMPUTATIONAL DETAILS}

All quantum chemical calculations were carried out using density functional theory (DFT). ${ }^{40}$ Time-dependent methodologies ${ }^{41-43}$ were applied together with the B3PW91 functional of Perdew and Wang ${ }^{44-47}$ for all computations of singlet excited electronic states (B3PW91 differs from the better known $\mathrm{B}^{2} \mathrm{LYP}^{48}$ by the non-local correlation term). The B3LYP functional modified with the Coulomb-attenuating method (CAM-B3LYP) ${ }^{49}$ was applied in its conventional form to predict the energetic separation between the ground and the lowest triplet state. The Dunning-type basis set aug-cc-pVTZ ${ }^{50,51}$ was applied in all computations of this sort and supplied geometries for different electronic states, corresponding harmonic vibrational frequencies, and energies of transitions from the ground to excited electronic states. 
To take into account the anharmonicity and inaccuracies of the applied theory, vibrational frequencies were scaled with the factor of $0.96,{ }^{52,53}$ for ground state DFT as well as for excited state TD-DFT computations. For the ground state, IR absorption intensities and Raman activities were also predicted. Linearity of the structure in the excited singlet electronic states was verified by optimizations starting from the bent geometry at the CIS/aug-cc-pVDZ ${ }^{50,51,54}$ level and inspection of vibrational frequencies (checking for the degeneracy of bending modes and for the possible occurrence of imaginary frequencies) at both CIS and DFT levels.

Special attention was paid to the formally forbiden $\widetilde{B}{ }^{1} \Delta-\tilde{X}^{1} \Sigma^{+}$system, where vibronic bands could be observed due to Herzberg-Teller coupling with a $\pi$-symmetry vibration. In order to identify that promoting mode, we have carried out a series of transition intensity (oscillator strength) calculations for the molecule distorted by each of the bendings. The vector representing the change was always parallel to a given normal coordinate and had a length of $0.1 \AA$. (Of note, when the movement along a bending normal coordinate of $\mathrm{HC}_{9} \mathrm{~N}$ is considered, shifts between the equilbrium ground state $(\tilde{X}, \mathrm{v}=0)$ geometry and any of the two $\tilde{B}$-state vibrational wavefunction $\left|\Psi_{\mathrm{v}=1}\right|$ maxima are on the order of $0.1 \AA$ A.) The Herzberg-Teller effect was assumed to be significant if the coupling to a given $\pi$-symmetry vibrational mode, simulated as outlined above, produced the oscillator strength of at least 0.0001 .

The GAUSSIAN 09 (Rev. B. 01) program was used for all computations ${ }^{55}$ while Jmol, ${ }^{56}$ Gabedit, $^{57}$ and Chemcraft ${ }^{58}$ were used for preparation of inputs and visualization of outputs. Additional computations were performed by DALTON $2.0^{59}$ at the CC2/cc-pVDZ level ${ }^{60-62}$ in order to predict the dominant character of the transitions.

\section{RESULTS AND DISCUSSION}

\section{$\underline{\text { Theoretical predictions }}$}

Theoretical predictions for the excited electronic states of $\mathrm{HC}_{9} \mathrm{~N}$ are listed in Table 1. In Figure 1, the corresponding molecular geometries are compared to that of the ground state. The DFT- 
derived ground-state structure matches the experimental one reasonably well and suggests that the computational level used is sufficient for this application. The interatomic distances in states $\tilde{A}, \tilde{B}$ and $\tilde{a}$, differ by less than $0.7 \mathrm{pm}$ and, compared to $\tilde{X}$, the geometry in these excited states corresponds to an elongation of triple bonds and shortening of the $\mathrm{CC}$ single bonds. The electronic structures of $\tilde{A}, \tilde{B}$, and $\tilde{a}$, together with that of the $\tilde{E}$ state, come mainly from the HOMO-LUMO excitation. The $\tilde{E}$ state geometry, however, slightly differs from those of the three other HOMO-LUMO states, especially in the middle of the chain, where there is a less pronounced length alternation of consecutive carbon-carbon bonds. The lowest-energy fully allowed electronic excitation is $\tilde{E}^{1} \Sigma^{+}-\tilde{X}^{1} \Sigma^{+}$. Orbitally forbidden $\widetilde{B}^{1} \Delta-\tilde{X}^{1} \Sigma^{+}$transitions may however also be quite important (as shown for $\mathrm{HC}_{3} \mathrm{~N}^{63-65}$ and $\mathrm{HC}_{5} \mathrm{~N}^{66}$ ), gaining sizable intensity via Herzberg-Teller vibronic coupling.

Table 1. Energy (eV) and Oscillator Strength for Transitions Involving the Ground $\left(X^{1} \Sigma^{+}\right)$and Excited Electronic States of $\mathrm{HC}_{9} \mathrm{~N}$ Derived at the B3PW91/aug-cc-pVTZ Level of Theory. Wavelengths (nm) Corresponding to the Transitions are Given in Parentheses.

\begin{tabular}{|c|c|c|c|c|}
\hline State & $\begin{array}{c}\text { Dominant orbital } \\
\text { excitation }\end{array}$ & $\begin{array}{c}\text { Vertical transition } \\
\text { energy }(\lambda)\end{array}$ & $f^{b}$ & $0-0$ transition energy $(\lambda)$ \\
\hline$\tilde{A}^{1} \Sigma^{-}$ & $5 \pi \rightarrow 1 \pi^{*}$ & $2.84(437)$ & 0 & $2.39(519)$ \\
\hline$\tilde{B}^{1} \Delta$ & $5 \pi \rightarrow 1 \pi^{*}$ & $2.93(423)$ & 0 & $2.52(492)$ \\
\hline$\tilde{C}^{1} \Sigma^{-}$ & $4 \pi \rightarrow 1 \pi^{*}$ & $4.38(283)$ & 0 & $4.10(302)$ \\
\hline$\widetilde{D}^{1} \Delta$ & $4 \pi \rightarrow 1 \pi^{*}$ & $4.53(274)$ & 0 & $4.27(290)$ \\
\hline$\tilde{E}^{1} \Sigma^{+}$ & $5 \pi \rightarrow 1 \pi^{*}$ & $5.06(245)$ & 2.8 & $4.88(254)$ \\
\hline$\tilde{F}^{1} \Sigma^{-}$ & $5 \pi \rightarrow 2 \pi^{*}$ & $5.30(234)$ & 0 & $4.98(249)$ \\
\hline$\tilde{G}^{1} \Delta$ & $5 \pi \rightarrow 2 \pi^{*}$ & $5.32(233)$ & 0 & $5.00(248)$ \\
\hline$\widetilde{H}^{1} \Sigma^{+}$ & $4 \pi \rightarrow 1 \pi^{*}, 5 \pi \rightarrow 2 \pi^{*}$ & $5.40(230)$ & 1.7 & $5.11(243)$ \\
\hline$\tilde{a}^{3} \Sigma^{+}$ & $5 \pi \rightarrow 1 \pi^{*}$ & - & - & $2.16(574)$ \\
\hline${ }^{a}$ Ground state electronic configuration: [core] $(1 \sigma)^{2}(2 \sigma)^{2}(3 \sigma)^{2}(4 \sigma)^{2}(5 \sigma)^{2}(6 \sigma)^{2}(7 \sigma)^{2}(8 \sigma)^{2}(9 \sigma)^{2}(10 \sigma)^{2}(1 \pi)^{4}(2 \pi)^{4}$ \\
$(11 \sigma)^{2}(3 \pi)^{4}(4 \pi)^{4}(5 \pi)^{4}\left(1 \pi^{*}\right)^{0}\left(2 \pi^{*}\right)^{0}\left(1 \sigma^{*}\right)^{0}$. \\
${ }^{b}$ Value of zero indicates $f<5 \cdot 10^{-5}$.
\end{tabular}


Figure $1 . \mathrm{HC}_{9} \mathrm{~N}$ geometry in its ground and excited electronic states as derived at the B3PW91/aug-cc-pVTZ level of theory. Interatomic distances in pm. Values listed for the excited electronic states are relative,

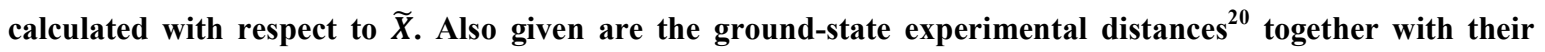
respective $\operatorname{CCSD}(T)$ predictions ${ }^{19}$. The states $\widetilde{a}, \widetilde{B}$, and $\widetilde{E}$ were experimentally observed in this work (entries listed in bold).

Vibrational frequencies characterizing $\tilde{X}, \tilde{B}$, and $\widetilde{E}$ states are listed in Table 2, together with $\tilde{X}$ state IR absorption intensities and Raman scattering activities. Predictions obtained for the remaining singlet excited states of Tab. 1 and Fig. 1 can be found in Tab. S1 of the Supporting Information. Table 2 provides also a short description of vibrational modes (see Tab. S2 of the Supporting Information for the graphical representations). The corresponding modes closely resemble one another in these three electronic states with the exception of modes in the 2000$2200 \mathrm{~cm}^{-1}$ range where the vibrations represent diverse mixtures of $\mathrm{C} \equiv \mathrm{C}$ and $\mathrm{C} \equiv \mathrm{N}$ stretches. 
Table 2. Harmonic Vibrational Frequencies (in $\mathrm{cm}^{-1}$; Scaling Factor 0.96) for the Ground and Two Excited Electronic States of $\mathrm{HC}_{9} \mathrm{~N}$, as Derived at the B3PW91/aug-cc-pVTZ Level of Theory. IR Intensity and Raman Activity Units are $\mathrm{km} / \mathrm{mol}$ and $\AA^{4} / \mathrm{amu}$, Respectively.

\begin{tabular}{|c|c|c|c|c|c|}
\hline \multirow[b]{2}{*}{ Mode } & \multicolumn{2}{|r|}{$\tilde{X}$} & $\widetilde{B}$ & $\tilde{E}$ & \multirow[b]{2}{*}{ Short description $^{a}$} \\
\hline & Freq. & $\begin{array}{c}\text { IR intensity/ } \\
\text { Raman activity }\end{array}$ & Freq. & Freq. & \\
\hline & \multicolumn{3}{|c|}{$\sigma$ symmetry } & & \\
\hline$v_{1}$ & 3324 & $193 / 12$ & 3318 & 3298 & $v \mathrm{CH}$ \\
\hline$v_{2}$ & 2250 & $109 / 1922$ & 2098 & 2150 & Mixture of $v \mathrm{C} \equiv \mathrm{C}$ and $v \mathrm{C} \equiv \mathrm{N}$ \\
\hline$v_{3}$ & 2201 & $1.5 / 473$ & 2059 & 2059 & Mixture of $v \mathrm{C} \equiv \mathrm{C}$ and $v \mathrm{C} \equiv \mathrm{N}$ \\
\hline$v_{4}$ & 2146 & $291 / 32763$ & 2000 & 2033 & Mixture of $v C \equiv C$ and $v C \equiv N$ \\
\hline$v_{5}$ & 2122 & $8.2 / 3523$ & 1900 & 1956 & Mixture of $v \mathrm{C} \equiv \mathrm{C}$ and $v \mathrm{C} \equiv \mathrm{N}$ \\
\hline$v_{6}$ & 2037 & $0.1 / 1511$ & 1848 & 1893 & Mixture of $v C \equiv C$ and $v C \equiv N$ \\
\hline$v_{7}$ & 1369 & $0.5 / 0.3$ & 1479 & 1346 & Adjacent $v C$-C out of phase \\
\hline$v_{8}$ & 1074 & $0.5 / 38$ & 1106 & 1071 & $v \mathrm{C}-\mathrm{CH}+v \mathrm{C}-\mathrm{CN}$ in phase \\
\hline$v_{9}$ & 736 & $3.9 / 1.5$ & 741 & 730 & $v \mathrm{C}-\mathrm{CH}+v \mathrm{C}-\mathrm{CN}$ out of phase \\
\hline \multirow[t]{2}{*}{$v_{10}$} & 376 & $0.3 / 1.6$ & 386 & 374 & Chain stretch \\
\hline & \multicolumn{3}{|c|}{$\pi$ symmetry } & & \\
\hline$v_{11}$ & 764 & $0.1 / 39$ & 754 & 712 & Chain bending (zig-zag; 9 nodes) \\
\hline$v_{12}$ & 640 & $40 / 13$ & 559 & 562 & $\delta \mathrm{CH}$ \\
\hline$v_{13}$ & 578 & $0.5 / 0.0$ & 547 & 519 & Chain bending ( 8 nodes) \\
\hline$v_{14}$ & 511 & $4.2 / 12$ & 486 & 458 & Chain bending ( 7 nodes) \\
\hline$v_{15}$ & 451 & $0.1 / 0.9$ & 432 & 419 & Chain bending ( 6 nodes) \\
\hline$v_{16}$ & 301 & $4.0 / 0.0$ & 309 & 253 & Chain bending ( 5 nodes) \\
\hline$v_{17}$ & 198 & $0.1 / 1.1$ & 191 & 147 & Chain bending ( 4 nodes) \\
\hline$v_{18}$ & 107 & $4.4 / 1.2$ & 105 & 88 & Chain bending ( 3 nodes) \\
\hline$v_{19}$ & 40 & $0.1 / 0.9$ & 39 & 35 & Chain bending ( 2 nodes) \\
\hline
\end{tabular}




\section{Detection of $\mathrm{HC}_{2} \underline{\mathrm{N}}$}

Since both $\mathrm{C}_{4} \mathrm{H}_{2}$ and $\mathrm{HC}_{5} \mathrm{~N}$ precursors are strong phosphorescence emitters ${ }^{66,67}$ with long vibronic progressions in the UV-visible range, it was important to have reliable predictions concerning the electronic spectroscopy of $\mathrm{HC}_{9} \mathrm{~N}$, in order to unambiguously distinguish the product from its precursors.

In the homologous series of polyynes, UV absorption wavelengths have been shown to change almost linearly with the size of the chain. ${ }^{68,69}$ This can be simplistically rationalized by considering a classical particle-in-a-box model, where a valence electron (a 'particle') is delocalized in a system ('box') of conjugated bonds. ${ }^{68}$ Prior to the present study, phosphorescence of $\mathrm{HC}_{7} \mathrm{~N},{ }^{36} \mathrm{HC}_{5} \mathrm{~N}^{35}$ and $\mathrm{C}_{3} \mathrm{~N}^{-}$anion ${ }^{70}$ has been observed $\left(\mathrm{HC}_{3} \mathrm{~N}\right.$, isoelectronic with $\mathrm{C}_{3} \mathrm{~N}^{-}$, does not phosphoresce), and the wavelengths of the corresponding vibrationless $\tilde{a}-\tilde{X}$ emission origins were found to be linearly correlated with the length of the carbonnitrogen chain. ${ }^{36}$ Extrapolation of this empirical trend places the origin of $\mathrm{HC}_{9} \mathrm{~N}$ phosphorescence near $588 \mathrm{~nm}$ or $2.11 \mathrm{eV}$. CAM-B3LYP calculations (Table 1) predict a value of $574 \mathrm{~nm}$ or $2.16 \mathrm{eV}$ (Figure 2). 


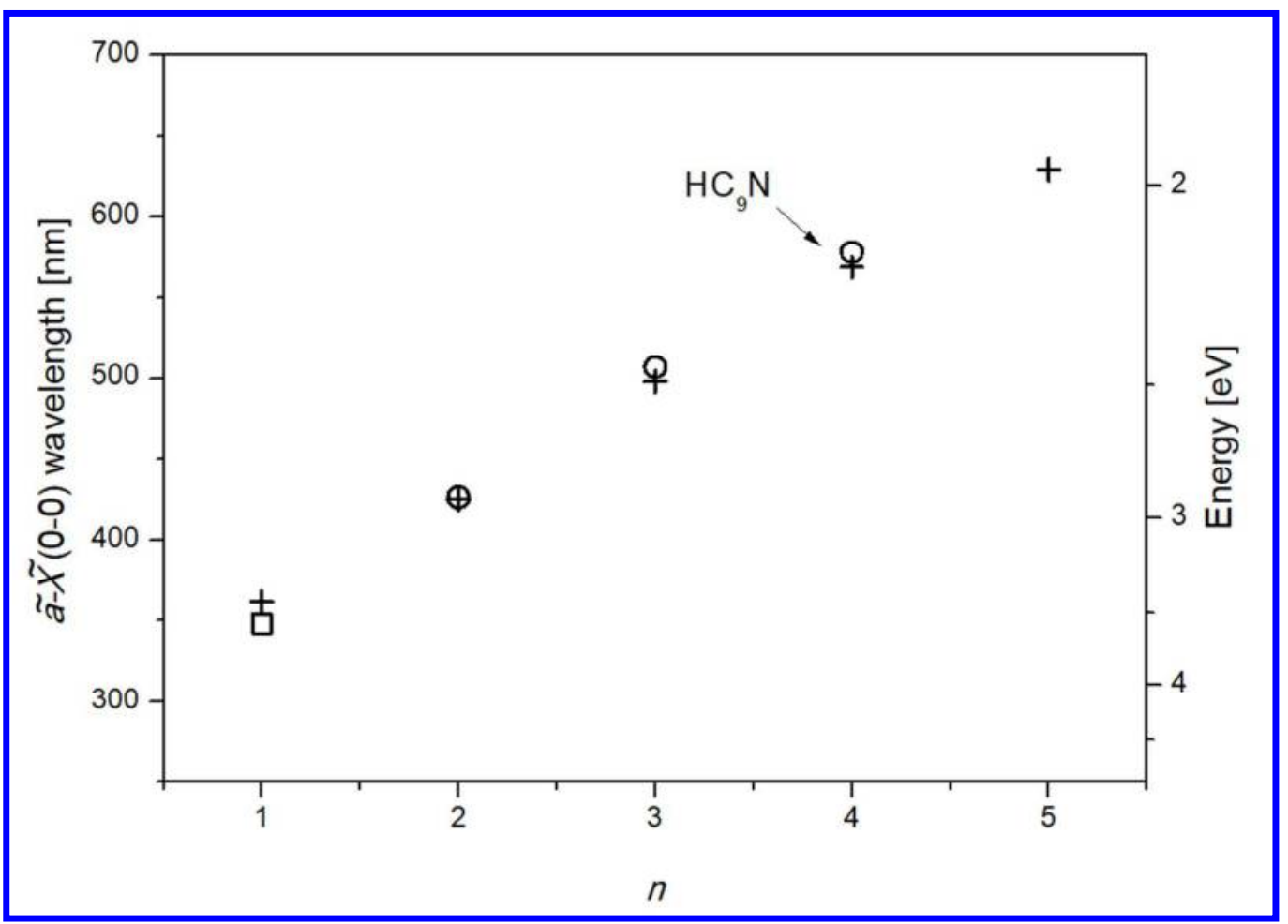

Figure 2. Phosphorescence origin wavelength as a function of carbon chain length for $\mathrm{HC}_{2 n+1} \mathrm{~N}$ molecules. Circles mark the experimental values for $\mathrm{Kr}$ matrices $\left(\mathrm{HC}_{3} \mathrm{~N}\right.$ does not phosphoresce; value observed for the isoelectronic $\mathrm{C}_{3} \mathrm{~N}^{-}$anion ${ }^{70}$ is entered for $n=1$ as an open square). Crosses correspond to CAM-B3LYP/aug-cepVTZ predictions. Experimental data for $\mathrm{HC}_{5} \mathrm{~N}$ and $\mathrm{HC}_{7} \mathrm{~N}$ come from Refs. 37,66.

While our CCD camera and spectrograph were well suited to record the anticipated $\mathrm{HC}_{9} \mathrm{~N}$ phosphorescence, we did not rely on exciting this emission with the ArF excimer laser (193 nm) employed for the photolysis. Instead, selective excitation of a sample previously subjected to extensive $193 \mathrm{~nm}$ irradiation was performed using a less powerful, tunable OPO operating in the expected region of $\tilde{E}-\tilde{X}$ transitions (around $250 \mathrm{~nm}$ ). The corresponding dispersed phosphorescence spectra showed a $578 \mathrm{~nm}$ band which was the origin of a vibronic progression and whose excitation spectrum exhibited strong bands between 240 and $260 \mathrm{~nm}$ (as shown later). Once the emission and excitation wavelengths of $\mathrm{HC}_{9} \mathrm{~N}$ phosphorescence were determined, it was possible to follow the photochemical reaction kinetics in a fresh $\mathrm{Kr} / \mathrm{C}_{4} \mathrm{H}_{2} / \mathrm{HC}_{5} \mathrm{~N}$ sample. For these measurements, the intensity of the $578 \mathrm{~nm}$ emission induced via OPO excitation (273.7 nm) was monitored over the course of $193 \mathrm{~nm}$ excimer laser irradiation. Time delays on the 
order of a few to tens of ms between the OPO, excimer laser, and signal acquisition were fixed to avoid, as much as possible, any perturbation of the collected spectrum by the phosphorescence of precursors excited at $193 \mathrm{~nm}$. The time evolution of the resulting signal is depicted in Figure 3. No signal could be seen for an unphotolyzed sample showing that the emission certainly came from a photoproduct. The growth rate of this species decreased with irradiation time.

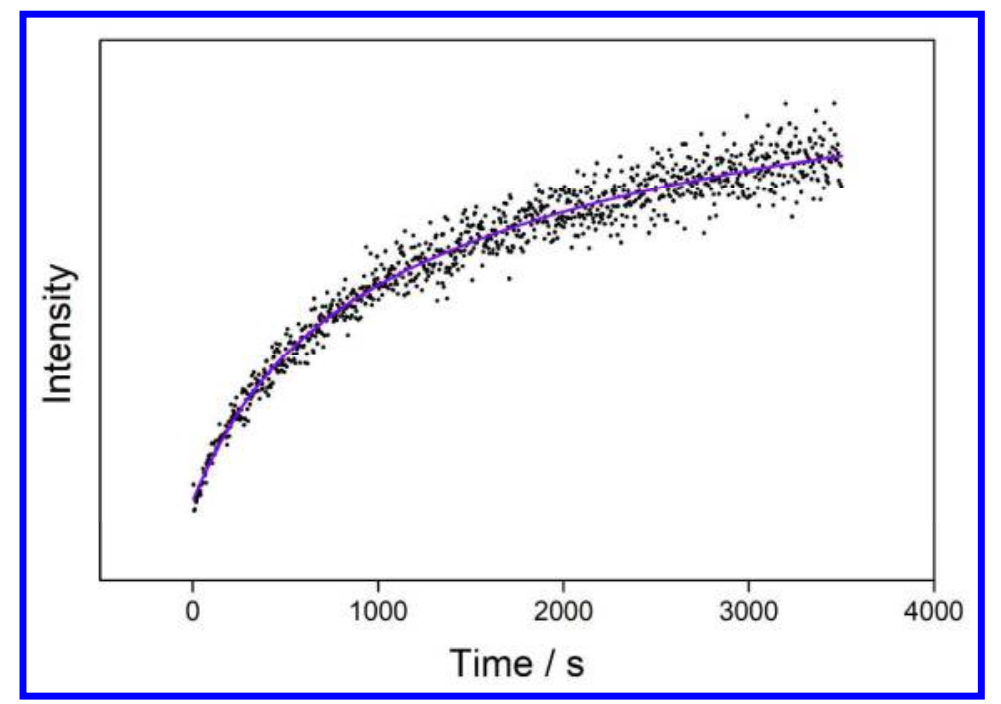

Figure 3. Time evolution of $\mathrm{HC}_{9} \mathrm{~N}$ formation, as monitored by intensity of phosphorescence (excited at 273.7 $\mathrm{nm}$ and measured at $578 \mathrm{~nm})$ emitted from an irradiated $(193 \mathrm{~nm}) \mathrm{Kr} / \mathrm{C}_{4} \mathrm{H}_{2} / \mathrm{HC}_{5} \mathrm{~N}(1000 / 1 / 1)$ matrix. Solid line added for better visibility of the trend.

Phosphorescence and vibrational modes of the ground state

The luminescence presented in Figure 4 was emitted from UV-photolyzed $\mathrm{Kr} / \mathrm{C}_{4} \mathrm{H}_{2} / \mathrm{HC}_{5} \mathrm{~N}$ matrices. The first intense band at $17300 \mathrm{~cm}^{-1}(578 \mathrm{~nm}, 2.14 \mathrm{eV})$ is the origin of the $\tilde{a}-\tilde{X}$ transition of $\mathrm{HC}_{9} \mathrm{~N}$ and almost matches the theoretical prediction. This band is clearly correlated to those around 15150 and $13000 \mathrm{~cm}^{-1}$; all three groups of spectral features share a common phosphorescence excitation spectrum. Two vibronic bands, separated from the $0-0$ transition by $2143 \mathrm{~cm}^{-1}$ and $2170 \mathrm{~cm}^{-1}$, can be distinguished in the spectrum and are indicative of excitation of triple bond stretching vibrations. The former can be assigned to mode $v_{4}$ of $\mathrm{HC}_{9} \mathrm{~N}$ ( $c f$. predicted $\tilde{X}$-state frequencies listed in Table 2). This mode corresponds to the in-phase stretching of the 
three central $\mathrm{C} \equiv \mathrm{C}$ bonds (see Table $\mathrm{S} 2$ ). Mode $v_{4}$ is likely to play the key role in phosphorescence transitions, as it deforms the molecule (alternately shrinking and elongating the consecutive bonds along the chain) in a similar fashion as predicted for electronic transitions between states $\tilde{X}$ and $\tilde{a}$ (Fig. 1). Stretching modes having similar characteristics also shaped the main vibronic progressions in low-temperature phosphorescence of $\mathrm{HC}_{5} \mathrm{~N}^{35,66}$ and $\mathrm{HC}_{7} \mathrm{~N}^{36,37}$ These modes also had the highest Raman activity in ground electronic states of the said cyanopolyynes. This is also true for the Raman activity of $v_{4}$ in the ground electronic state of $\mathrm{HC}_{9} \mathrm{~N}$ (Table 2). The spacing of $2170 \mathrm{~cm}^{-1}$ is unlikely to be associated with $v_{3}$. There is a poor match with the predicted $v_{3}$ value of $2201 \mathrm{~cm}^{-1}$ and atomic displacements involved in the vibration (Table 2 and Table S2) are qualitatively different from those of $v_{4}$. We propose assignment of this spacing to $2 v_{8}$ (harmonic prediction: $2 \cdot 1074 \mathrm{~cm}^{-1}$ ). Mode $v_{8}$ is C-C stretching, resembling gerade symmetry. A similar vibronic spacing, produced by a C-C stretching overtone $\left(2 v_{5}\right)$, was observed for $\mathrm{HC}_{5} \mathrm{~N} .{ }^{66}$ Assignments of several vibronic bands of $\mathrm{HC}_{9} \mathrm{~N}$ in $\mathrm{Kr}$ and in $\mathrm{Ar}$ hosts are proposed in Table 3 . A $\pi$-symmetry mode, possibly $v_{14}$, was observed only in Ar (497 $\mathrm{cm}^{-1}$ with respect to the vibrationless origin); an alike bending-mode vibronic band of $\mathrm{HC}_{5} \mathrm{~N}$ phosphorescence was intense in $\mathrm{Ar}$ and weak in $\mathrm{Kr}^{66}$ 


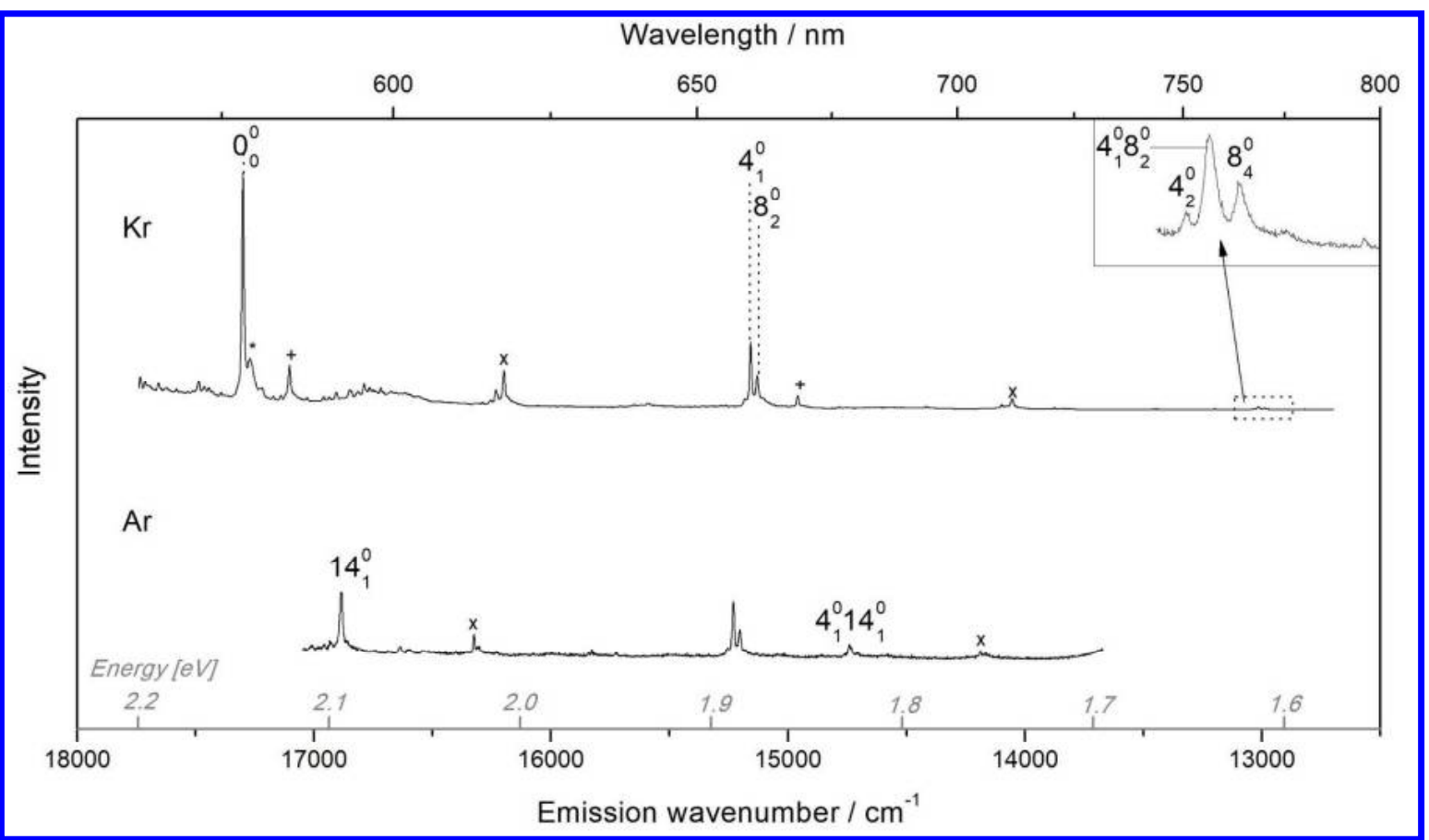

Figure 4. $\mathrm{HC}_{9} \mathrm{~N}-$-dominated phosphorescence of photolyzed $(193 \mathrm{~nm}) \mathrm{Kr} / \mathrm{C}_{4} \mathrm{H}_{2} / \mathrm{HC}_{5} \mathrm{~N}(1000 / 1 / 1)$ (upper) and $\mathrm{Ar} / \mathrm{C}_{4} \mathrm{H}_{2} / \mathrm{HC}_{5} \mathrm{~N}(1000 / 1 / 1)$ (lower) matrices excited at $36540 \mathrm{~cm}^{-1}(273.7 \mathrm{~nm})$ and $41440 \mathrm{~cm}^{-1}(241.3 \mathrm{~nm})$, respectively. Bands marked with '+' belong to additional photolysis products (as determined with the analysis of phosphorescence excitation spectra). The asterisked band is interpreted as being due to a secondary matrix site. Bands marked with ' $x$ ' are assigned to $C_{10} N_{2}$ phosphorescence (to be reported separately).

Table 3. Wavenumbers (in $\mathrm{cm}^{-1}$ ) of Electronic Emission Bands Assigned to $\mathrm{HC}_{9} \mathrm{~N}$ Phosphorescence in Solid Ar and Kr.

\begin{tabular}{|c|c|c|c|c|}
\hline \multicolumn{2}{|c|}{ Ar } & \multicolumn{2}{c|}{ Kr } & \multirow{2}{*}{ Assignment } \\
\cline { 1 - 4 } Absolute & Relative $^{a}$ & Absolute & Relative $^{a}$ & \\
\hline 17379 & 0 & 17300 & 0 & $0_{0}^{0}$ \\
\hline 16881 & 497 & & & $14_{1}^{0}$ \\
\hline 15231 & 2148 & 15157 & 2143 & $4_{1}^{0}$ \\
\hline 15205 & 2174 & 15130 & 2170 & $8_{2}^{0}$ \\
\hline 14740 & 2639 & & & $4_{1}^{0} 14_{1}^{0}$ \\
\hline & & 13038 & 4262 & $4_{2}^{0}$ \\
\hline & & 13018 & 4282 & $4_{1}^{0} 8_{2}^{0}$ \\
\hline
\end{tabular}


No IR absorption attributable to $\mathrm{HC}_{9} \mathrm{~N}$ could be measured. This is not surprising, considering that earlier, analogous experiments aimed at synthesizing longer chains from $\mathrm{HC}_{3} \mathrm{~N}+\mathrm{C}_{2} \mathrm{H}_{2}$ or from $\mathrm{HC}_{5} \mathrm{~N}+\mathrm{C}_{2} \mathrm{H}_{2}$ led to fairly weak IR bands for $\mathrm{HC}_{5} \mathrm{~N},{ }^{34}$ and bands near the limit of $\mathrm{HC}_{7} \mathrm{~N}$ detection, ${ }^{36}$ respectively. Furthermore, the yield of (poly)acetylene+cyano(poly)acetylene reactions in rigid matrices is likely decreasing with the increasing size of a cyanopolyacetylenic product.

The phosphorescence decay time in solid krypton, $3.9 \pm 0.1 \mathrm{~ms}(0-0$ band $)$, was for $\mathrm{HC}_{9} \mathrm{~N}$ smaller than for other members of the $\mathrm{HC}_{2 n+1} \mathrm{~N}$ homologous series including $\mathrm{HC}_{5} \mathrm{~N}(40 \mathrm{~ms})^{66}$ and $\mathrm{HC}_{7} \mathrm{~N}(8.2 \mathrm{~ms})^{71}$. The increased number of internal degrees of freedom presumably promotes non-radiative relaxation channels, decreasing the triplet state lifetime. As chains get longer, the phosphorescence lifetime can be expected to decrease further.

\section{$\underline{\text { Singlet excited electronic states }}$}

The excitation spectrum of $\mathrm{HC}_{9} \mathrm{~N}$ phosphorescence revealed two distinct electronic systems, in $26000-34000 \mathrm{~cm}^{-1}$ and $35000-50000 \mathrm{~cm}^{-1}$ regions.

The first (Figure 5), characterized by a series of bands spaced by $\sim 2100 \mathrm{~cm}^{-1}$, was assigned to $\tilde{B}^{1} \Delta-\tilde{X}^{1} \Sigma^{+}$transitions, based on very similar patterns already observed in UV absorption and/or phosphorescence excitation spectra for the smaller molecules of the series: $\mathrm{HC}_{3} \mathrm{~N},{ }^{63-65}$ $\mathrm{HC}_{5} \mathrm{~N},{ }^{66}$ and $\mathrm{HC}_{7} \mathrm{~N}^{72}$ Geometry changes implied by $\tilde{B}-\tilde{X}$ and $\tilde{a}-\tilde{X}$ excitations are mutually similar (see Figure 1), therefore both systems are expected to feature alike vibronic patterns. One of possible choices for the mode responsible for the vibronic $\tilde{B}-\tilde{X}$ progression is $v_{3}$, because the corresponding vibrational motions of atoms in the $\tilde{B}$ state (see Table S2 for visualization) resemble those of $v_{4}$ in the ground electronic state ( $v_{4}$ already mentioned as prominently appearing in $\tilde{a}-\tilde{X}$ phosphorescence). While we cannot exclude the above possibility, we prefer to 
assign the $\tilde{B}-\tilde{X}$ progression to the stretching mode $v_{2}$, for which the predicted $\tilde{B}$-state frequency better matches the observed vibronic spacing (see Table 2).

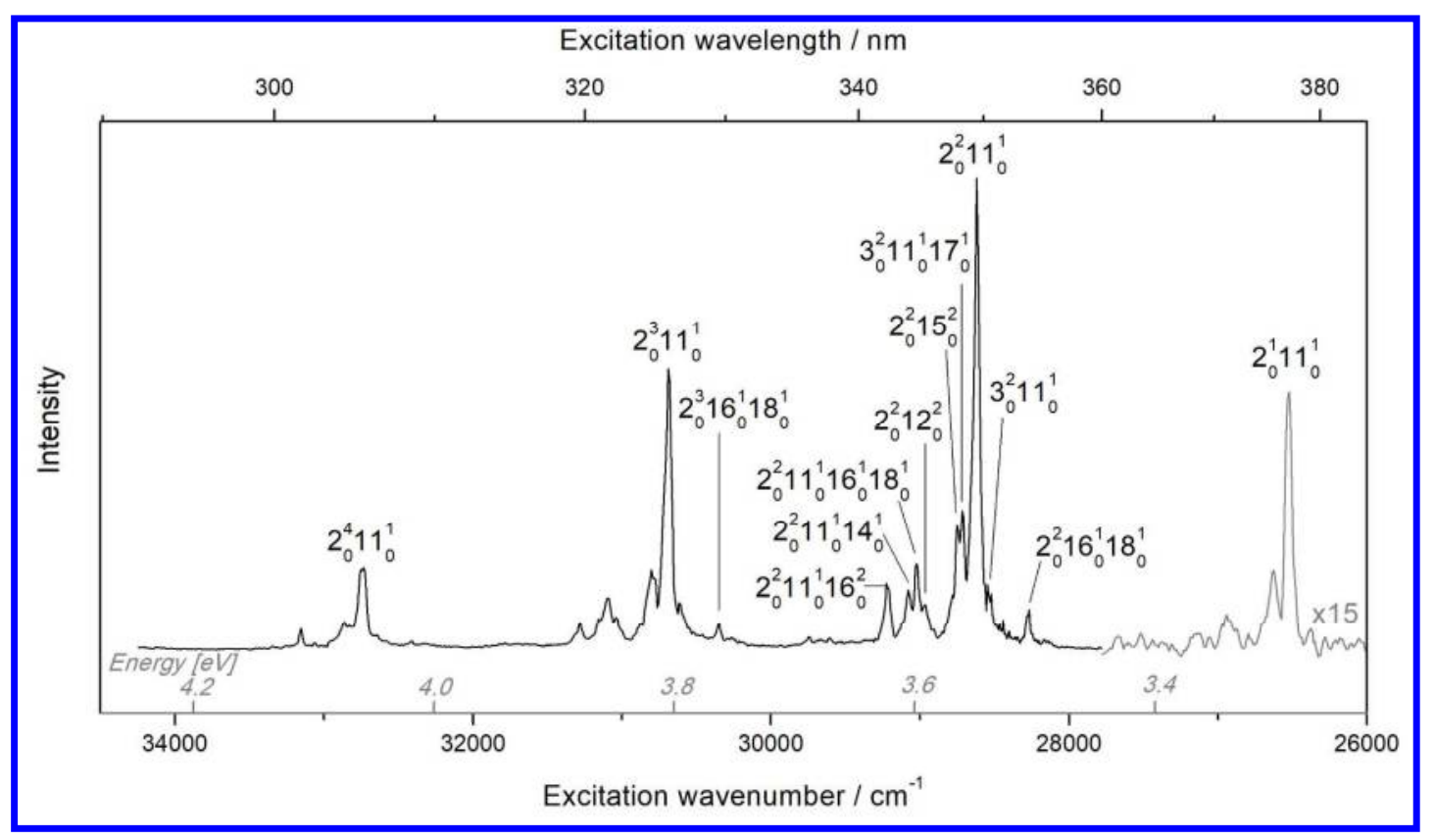

Figure 5. $\widetilde{B}^{1} \Delta-\widetilde{X}^{1} \Sigma^{+}$system detected in the phosphorescence excitation spectrum of $\mathrm{HC}_{9} \mathrm{~N}$, coming from a previously photolyzed $(193 \mathrm{~nm}) \mathrm{Kr} / \mathrm{C}_{4} \mathrm{H}_{2} / \mathrm{HC}_{5} \mathrm{~N}(1000 / 1 / 1)$ matrix. Detection centered at the most intense phosphorescence band $\left(17300 \mathrm{~cm}^{-1}, 2.14 \mathrm{eV}\right)$. Wavelength-dependent laser intensity variations might distort the phosphorescence intensity pattern.

No band corresponding to the $\tilde{B}-\tilde{X}$ origin is expected to appear in the spectrum, since the transitions of this orbital symmetry-forbidden system require coupling to a $\pi$-symmetry vibrational mode. In the analysis of respective analogous $\tilde{B}-\tilde{X}$ transitions, such $\pi$-symmetry modes were identified as $v_{5}$ for $\mathrm{HC}_{3} \mathrm{~N},{ }^{63-65} v_{8}$ for $\mathrm{HC}_{5} \mathrm{~N},{ }^{66}$ and $v_{10}$ and/or $v_{12}$ for $\mathrm{HC}_{7} \mathrm{~N} .{ }^{72}$ Looking at the common features of the above vibrations, one can find that: $(i)$ these are the chain bendings of the highest energy, sharing specific, qualitatively similar molecular distortion patterns, and (ii) their ground and excited state frequencies are very different. Moreover, in the case of Ar matrix-isolated $\mathrm{HC}_{5} \mathrm{~N}$, the $v_{8}$ mode stands out in the phosphorescence spectrum. ${ }^{66}$ For $\mathrm{HC}_{9} \mathrm{~N}$, it was in principle possible to assign the observed vibronic features assuming the participation of either $v_{11}, v_{12}$, or $v_{14}$ (predicted $\tilde{B}$-state wavenumbers: $754 \mathrm{~cm}^{-1}, 559 \mathrm{~cm}^{-1}$ and 
$486 \mathrm{~cm}^{-1}$, respectively). To further narrow down which of the three modes is involved, $\tilde{B}-\tilde{X}$ oscillator strength values were derived for $\widetilde{B}$-state molecular geometry slightly distorted along respective normal bending coordinates (see Computational Details). A noticeable oscillator strength has appeared only for the geometry distorted along the coordinate of mode $v_{11}$. This coarse computational simulation of the Herzberg-Teller coupling suggests that the $\tilde{B} \leftarrow \tilde{X}$ absorption may gain probability via excitation of the $v_{11}$ mode in the upper electronic state. The corresponding assignment is given in Figure 5 and Table 4 using the theoretical values of Table 2 for vibrational frequencies. Assuming that $v_{11}$ is the promoting mode, the origin of $\tilde{B}-\tilde{X}$ can be expected approximately $750 \mathrm{~cm}^{-1}$ below the first detectable band of the $v_{2}$ progression $(26530$ $\left.\mathrm{cm}^{-1}\right)$, namely at $\sim 25780 \mathrm{~cm}^{-1}(388 \mathrm{~nm})$. However, DFT calculations (Table 1) locate the vibrationless $\tilde{B}-\tilde{X}$ origin much lower, at $492 \mathrm{~nm}\left(20330 \mathrm{~cm}^{-1}\right)$. As taken into account in Figure 5 and Table 4, this implies the presence of at least one additional, less energetic element of the $v_{2}$ progression and a possible placement of the system origin around $23700 \mathrm{~cm}^{-1}$ (corresponding to $422 \mathrm{~nm}$, which is out of the detection range limited here to $\lambda<400 \mathrm{~nm}$ ).

Table 4. Vibronic Bands in the $\widetilde{B}^{1} \Delta-\widetilde{X}^{1} \Sigma^{+}$Electronic System of $\mathrm{HC}_{9} \mathrm{~N}$ in Solid Krypton, Revealed by the Phosphorescence Excitation Spectrum.

\begin{tabular}{|c|c|c|}
\hline \multicolumn{2}{|c|}{ Frequency $\left(\mathrm{cm}^{-1}\right)$} & Assignment \\
\cline { 1 - 2 } Absolute & Relative $^{a}$ & $\mathbf{2}_{\mathbf{0}}^{\mathbf{1} 1 \mathbf{1}_{\mathbf{0}}^{\mathbf{1}}}$ \\
\hline $\mathbf{2 6 5 3 3}$ & $\mathbf{0}$ & $2_{0}^{1} 11_{0}^{1} 16_{0}^{1} 18_{0}^{1}$ \\
\hline 26925 & 392 & $2_{0}^{1} 11_{0}^{1} 16_{0}^{2}$ \\
\hline 27150 & 617 & $2_{0}^{2} 17_{0}^{1} 18_{0}^{1}$ \\
\hline 28165 & 1632 & $2_{0}^{2} 16_{0}^{1} 18_{0}^{1}$ \\
\hline 28274 & 1741 & $3_{0}^{2} 11_{0}^{1} / 2_{0}^{2} 14_{0}^{1} 17_{0}^{1}$ \\
\hline 28546 & 2013 & \\
\hline $\mathbf{2 8 6 2 3}$ & $\mathbf{2 0 9 0}$ & $\mathbf{2}_{\mathbf{0}}^{\mathbf{2} 11_{\mathbf{0}}^{\mathbf{1}}}$ \\
\hline 28719 & 96 & $3_{0}^{2} 11_{0}^{1} 17_{0}^{1} / 2_{0}^{2} 11_{0}^{1} 18_{0}^{1}$ \\
\hline
\end{tabular}




\begin{tabular}{|c|c|c|}
\hline 28753 & 130 & $2_{0}^{2} 15_{0}^{2}$ \\
\hline 28970 & 347 & $2_{0}^{2} 12_{0}^{2}$ \\
\hline 29027 & 404 & $2_{0}^{2} 11_{0}^{1} 16_{0}^{1} 18_{0}^{1}$ \\
\hline 29083 & 460 & $2_{0}^{2} 11_{0}^{1} 14_{0}^{1}$ \\
\hline 29225 & 602 & $2_{0}^{2} 11_{0}^{1} 16_{0}^{2}$ \\
\hline 29606 & 983 & $2_{0}^{2} 11_{0}^{1} 12_{0}^{1} 15_{0}^{1}$ \\
\hline 29743 & 1120 & $2_{0}^{2} 11_{0}^{1} 12_{0}^{2}$ \\
\hline 30267 & 1644 & $22_{0}^{3} 17_{0}^{1} 18_{0}^{1}$ \\
\hline 30349 & 1726 & $2_{0}^{3} 16_{0}^{1} 18_{0}^{1}$ \\
\hline 30613 & 1990 & $3_{0}^{3} 11_{0}^{1} / 2_{0}^{3} 14_{0}^{1} 17_{0}^{1}$ \\
\hline 30691 & 2068 & $2311_{0}^{1}$ \\
\hline 30780 & 89 & $3_{0}^{3} 11_{0}^{1} 17_{0}^{1} / 2_{0}^{3} 11_{0}^{1} 18_{0}^{1}$ \\
\hline 30807 & 116 & $2_{0}^{3} 15_{0}^{2}$ \\
\hline 31040 & 349 & $2_{0}^{3} 12_{0}^{2}$ \\
\hline 31098 & 407 & $2_{0}^{3} 11_{0}^{1} 16_{0}^{1} 18_{0}^{1}$ \\
\hline 31155 & 464 & $2_{0}^{3} 11_{0}^{1} 14_{0}^{1}$ \\
\hline 31281 & 590 & $22_{0}^{3} 11_{0}^{1} 16_{0}^{2}$ \\
\hline 32324 & 1633 & $2_{0}^{4} 17_{0}^{1} 18_{0}^{1}$ \\
\hline 32408 & 1717 & $2_{0}^{4} 16_{0}^{1} 18_{0}^{1}$ \\
\hline 32639 & 1948 & $3_{0}^{4} 11_{0}^{1} / 2_{0}^{4} 14_{0}^{1} 17_{0}^{1}$ \\
\hline 32734 & 2043 & $22_{0}^{4} 11_{0}^{1}$ \\
\hline 32828 & 94 & $3_{0}^{4} 11_{0}^{1} 17_{0}^{1} / 2_{0}^{4} 11_{0}^{1} 18_{0}^{1}$ \\
\hline 32862 & 128 & $22_{0}^{4} 15_{0}^{2}$ \\
\hline 33152 & 418 & $2_{0}^{4} 11_{0}^{1} 16_{0}^{1} 18_{0}^{1}$ \\
\hline
\end{tabular}

${ }^{a}$ Relative values give distances from the previous member of the $2_{0}^{n} 11_{0}^{1}$ progression (bold).

The systematic bathochromic shift of $\tilde{B}-\tilde{X}$ spectra with increasing the $\mathrm{HC}_{2 n+1} \mathrm{~N}$ chain length is shown in Figure 6. While singlet-triplet energy splittings are well predicted by DFT (Figure 2), $\tilde{B}-\tilde{X}$ excitation energies are sizably underestimated (note that the ordinate axis in Figure 6 corresponds to wavelength). It is still true after accounting for a gas-to-matrix shift on the order 
of $5 \mathrm{~nm}$. Accidentally, our DFT-derived vertical transition energies match the experimental $\tilde{B}-\tilde{X}$ origin values. As exemplified e.g. by a recent study $^{73}$ for atoms, TD-B3PW91/aug-ccpVTZ excitation energies tend, on average, to be underestimated by a few percent. For the series of molecules investigated here, this TD-DFT error happens to have a similar size as the difference between vertical and vibrationless transitions. The plot adds credibility to the analysis of the $\mathrm{HC}_{9} \mathrm{~N}$ phosphorescence excitation spectrum presented above, and in particular to the ensuing derivation of the $\tilde{B}-\tilde{X}$ origin (at $\sim 422 \mathrm{~nm}$, represented by a black dot for $n=4$ ). Indeed, had our assignment of $2_{0}^{1} 11_{0}^{1}$ been incorrect, the first band of the progression would have had to be assigned to $2_{0}^{2} 11_{0}^{1}$, placing the system origin at $\sim 465 \mathrm{~nm}$. The red dot, depicting that latter possibility in Figure 6, spoils a trend set by lower $n$ values.

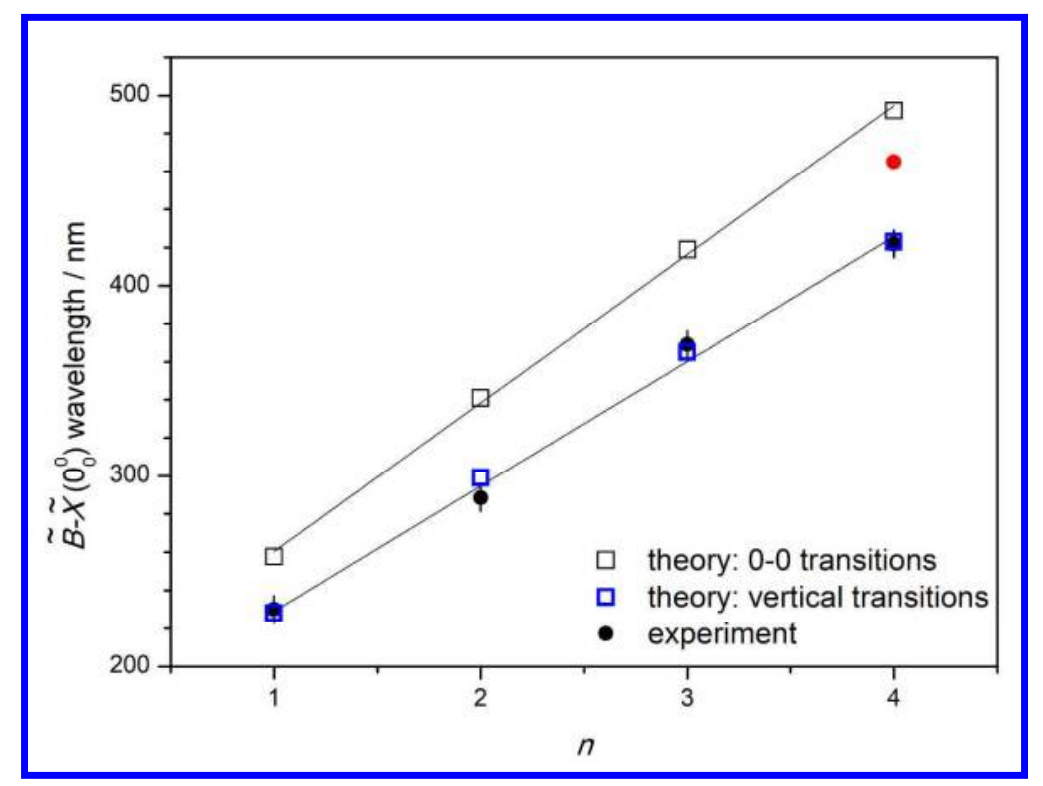

Figure 6. Dependence of the $\widetilde{B}-\widetilde{X}$ system origin wavelength on the carbon chain size $(n)$, for $\mathrm{HC}_{2 n+1} \mathrm{~N}$ molecules. Data based on Kr-matrix measurements, with the exception of $n=1$ measured in solid Ar (expected Kr-to-Ar wavelength shift is on the order of $0.5 \mathrm{~nm}$ ). Theoretical predictions carried out at the TDB3PW91/aug-cc-pVTZ level of theory. Red dot assumes misassignment of the first element of the progression (see text).

The second series consists of intense bands in the $35000-50000 \mathrm{~cm}^{-1}$ range of the $\mathrm{HC}_{9} \mathrm{~N}$ phosphorescence excitation spectrum and coincides with the spectral region of fully allowed $\tilde{E}$ 
${ }^{1} \Sigma^{+}-\tilde{X}^{1} \Sigma^{+}$and $\widetilde{H}^{1} \Sigma^{+}-\tilde{X}^{1} \Sigma^{+}$systems. These features can be compared (see Figure 7) to those of $\mathrm{HC}_{9} \mathrm{~N}$ observed in UV absorption spectra following the laser ablation of graphite in acetonitrile ${ }^{31}$ or to the ones found in a similar, though less detailed, UV absorption spectrum (not presented here) of a solution produced after immersion of a carbon arc in liquid ammonia. ${ }^{30}$ The DFTcomputed $\tilde{E}-\tilde{X}$ vertical excitation energy of $5.06 \mathrm{eV}\left(40820 \mathrm{~cm}^{-1}\right)$ reasonably corresponds to the maximal signal in Figure 7. The theoretically predicted vertical transitions of several electronic systems marked in Figure 7 point to a high density of states in the spectral window. This impedes reliable identification of individual bands. The complexity of the spectrum is presumably due to a mixing of vibronic transitions involving various electronic states. The lowest-energy band in this region, at $34600 \mathrm{~cm}^{-1}(4.29 \mathrm{eV})$, is weak and strongly red-shifted with respect to the predicted $\tilde{E}-\tilde{X}$ origin $(4.88 \mathrm{eV})$. Noteworthy, a substantial blue shift was observed between experimental and theoretical $\tilde{B}-\tilde{X}$ transitions (Figure 5). The $34600 \mathrm{~cm}^{-1}$ band may therefore belong to the $\widetilde{D}^{1} \Delta-\tilde{X}^{1} \Sigma^{+}$system, similar in nature to $\widetilde{B}^{1} \Delta-\tilde{X}^{1} \Sigma^{+}$ transitions, partly allowed owing to Herzberg-Teller vibronic coupling. Band progressions starting at $34600 \mathrm{~cm}^{-1}$ can be followed up to around $42000 \mathrm{~cm}^{-1}$. The vibronic spacings of approx. $1950 \mathrm{~cm}^{-1}$ could correspond to $\widetilde{D}$-state $\mathrm{C} \equiv \mathrm{C}$ stretchings. Two examples of such progressions are marked in Figure 7 (lower energy part). A very narrow band observed at $39610 \mathrm{~cm}^{-1}(4.91 \mathrm{eV})$ is possibly the origin of $\tilde{E}^{1} \Sigma^{+}-\tilde{X}^{1} \Sigma^{+}$system (which would make a good agreement with the theoretical prediction of Table 1). There are no evident candidates for other $\tilde{E}-\tilde{X}$ transitions. However, the pattern of intense bands in Figure 7 resembles the one obtained in the excitation spectrum of $\mathrm{HC}_{7} \mathrm{~N}^{37}$ around the first fully allowed electronic transition. Figure $\mathrm{S} 1$ of the Supporting Information provides a direct comparison of $\mathrm{HC}_{7} \mathrm{~N}$ and $\mathrm{HC}_{9} \mathrm{~N}$ observed in our experiments. It suggests that other bands of $\tilde{E}-\tilde{X}$ are present in this spectrum, contributing to the most intense features. Apart from the excitations to $\widetilde{D}$ and $\widetilde{E}$, the states $\tilde{G}$ or $\widetilde{H}$ may also be considered. The proposed assignment of progressions in Figure 7 points to $41970 \mathrm{~cm}^{-1}(5.20 \mathrm{eV})$ as the origin of the allowed $\widetilde{H}^{1} \Sigma^{+}-\widetilde{X}^{1} \Sigma^{+}$system (implying a 21 
slight blue shift from the theoretical value of Table 1). Just as in the case of $\widetilde{D}-\tilde{X}$ or $\widetilde{B}-\tilde{X}$, the vibronic progressions of $\tilde{G}-\tilde{X}$ and $\widetilde{H}-\tilde{X}$ should involve a specific triple bond stretching mode of the upper electronic state. A very tentative interpretation of the main bands discussed here is presented in Table 5.

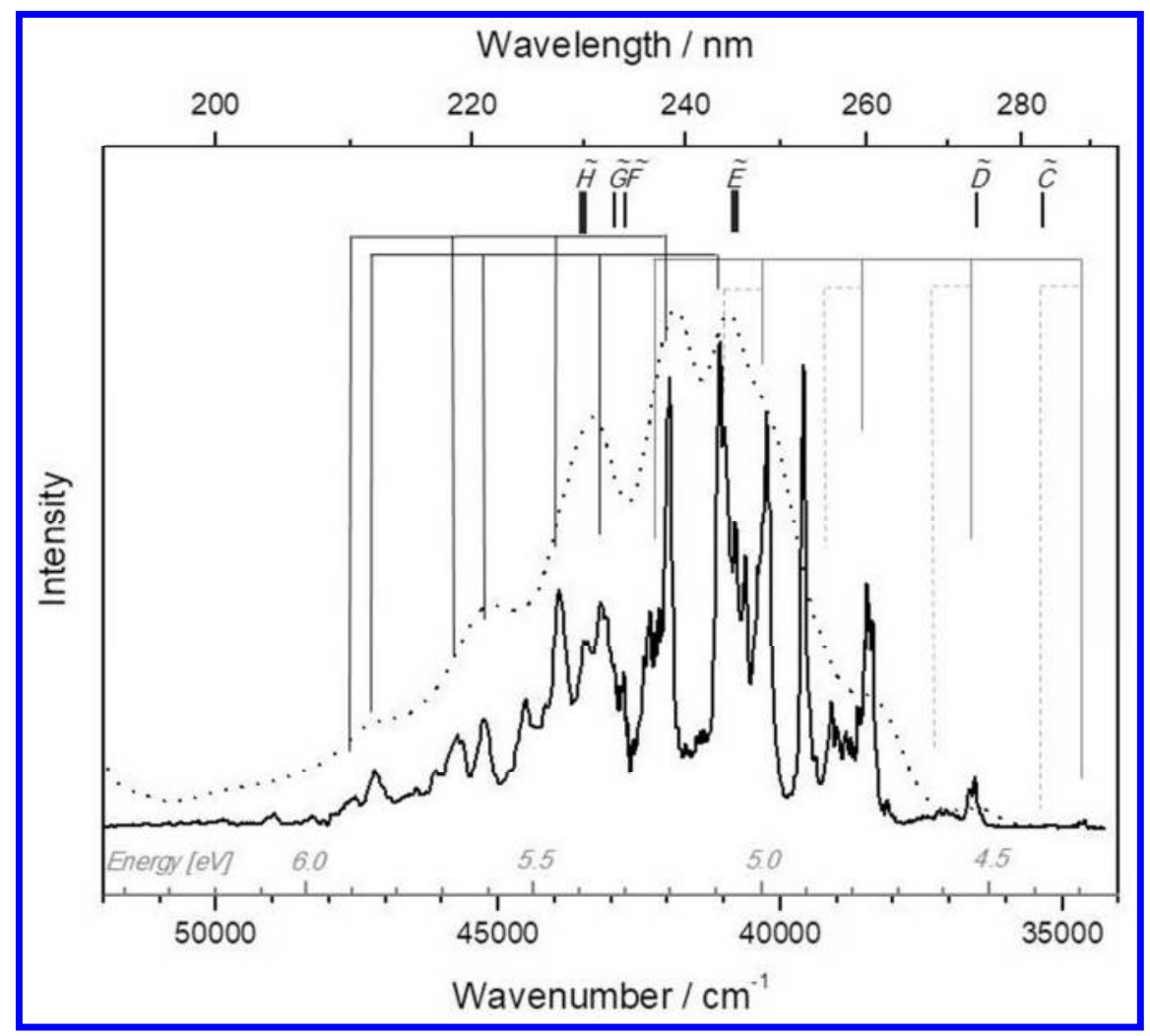

Figure 7. A fragment of the $\mathrm{HC}_{9} \mathrm{~N}$ phosphorescence excitation spectrum (detection centered at $17300 \mathrm{~cm}^{-1}$ ), measured for a previously photolyzed $(193 \mathrm{~nm}) \mathrm{Kr} / \mathrm{C}_{4} \mathrm{H}_{2} / \mathrm{HC}_{5} \mathrm{~N}(1000 / 1 / 1)$ sample, compared to the roomtemperature absorption spectrum of $\mathrm{HC}_{9} \mathrm{~N}$ in acetonitrile (dotted; Wakabayashi et al. $^{31}$ ). Wavelengthdependent laser intensity variations might distort the phosphorescence intensity pattern. Theoretically predicted energies of $\widetilde{X}$-originating vertical electronic excitations (data of Table 1) are indicated by top bars (bold ones for the fully allowed transitions). Also marked are the tentatively discerned vibronic progressions (see Table 5).

Couplings between nearly isoenergetic vibronic levels of adjacent electronic states can occur. These may have a sensitive dependence on the chemical environment. Interaction with solvent can lead to the broadening of spectral lines as can differences in temperature at which the spectrum was taken. Although not pictured here, the excitation spectrum of $\mathrm{HC}_{9} \mathrm{~N}$ in solid $\mathrm{Ar}$ 
1

2

3

4

5

6

7

8

9

10

exhibited, when compared to that registered for solid $\mathrm{Kr}$, non-uniform, matrix-related spectral shifts, as might be expected for a mixture of bands originating in various electronic systems. Low $\mathrm{S} / \mathrm{N}$ ratio in measurement of the Ar matrices did not allow for any vibronic patterns to be reliably discerned. Further studies in varied cryogenic matrices will help in proposing further spectral assignments and in verifying those of Table 5.

Table 5. Vibronic Bands Tentatively Attributed to Excited Singlet States in the HC ${ }_{9} \mathbf{N}$ Phosphorescence Excitation Spectrum of Figure 7.

\begin{tabular}{|c|c|}
\hline$\tilde{v}\left(\mathrm{~cm}^{-1}\right)$ & Provisional assignment \\
\hline 34598 & $\widetilde{D}$ (main progression) \\
\hline 34706 & $\widetilde{D}$ \\
\hline 35288 & $\widetilde{D}$ (secondary progression) \\
\hline 36554 & $\widetilde{D}$ (main progression) \\
\hline 36647 & $\widetilde{D}$ \\
\hline 37201 & $\widetilde{D}$ (secondary progression) \\
\hline 38358 & $\widetilde{D}$ (main progression) \\
\hline 38449 & $\widetilde{D}$ \\
\hline 39085 & $\widetilde{D}$ (secondary progression) \\
\hline 39605 & $\tilde{E}$ \\
\hline 40252 & $\widetilde{D}$ (main progression) \\
\hline 40986 & $\widetilde{D}$ (secondary progression) \\
\hline 41070 & $\tilde{G} / \tilde{E}$ \\
\hline 41973 & $\widetilde{H} / \tilde{E}$ \\
\hline 42148 & $\widetilde{D}$ (main progression) \\
\hline 43189 & $\tilde{G}$ \\
\hline 43921 & $\widetilde{H}$ \\
\hline 45247 & $\tilde{G}$ \\
\hline 45729 & $\widetilde{H}$ \\
\hline 47201 & $\tilde{G}$ \\
\hline
\end{tabular}


\begin{tabular}{|l|r|}
\hline 47534 & $\widetilde{H}$
\end{tabular}

Chain growth mechanism

For a bimolecular photochemical reaction between $\mathrm{C}_{4} \mathrm{H}_{2}$ and $\mathrm{HC}_{5} \mathrm{~N}$ (or between any other closed-shell precursors) to occur in a cryogenic matrix, at least one of these molecules must first undergo dissociation or electronic excitation. Following such an event, the excited molecule(s) or radical(s) may come into contact with a reaction partner. As mobility of large molecules is greatly hindered in cryogenic matrices, the reactants should be in the same or adjacent matrix sites for the process to proceed with any probability. Having reactants in the same matrix site may imply the existence of an intermolecular complex prior to excitation/dissociation. If reaction partners are in neighboring sites, some small fraction may already be appropriately oriented for reaction while others must undergo reorientation such that appropriate contact with a partner can be made. Reorientation energy may come from exothermicity of the preceding reactions or from local heating supplied by the photolysing radiation. This leaves a number of possible reaction mechanisms to be explored, some of which can be ruled out.

Dissociation of the cyanide containing species was previously suggested as being responsible for the formation of $\mathrm{HC}_{7} \mathrm{~N}$ in cryogenic matrices ${ }^{36}$ (reactions 1-3). This mechanism is consistent with that proposed by Cherchneff et al. for the formation of long chains in the ISM. ${ }^{16,17}$

$\mathrm{HC}_{2 n+1} \mathrm{~N}+h v \rightarrow \mathrm{H}^{\bullet}+\mathrm{C}_{2 n+1} \mathrm{~N}^{\bullet}$

$\mathrm{C}_{3} \mathrm{~N}^{\bullet}+\mathrm{HC}_{4} \mathrm{H} \rightarrow \mathrm{HC}_{7} \mathrm{~N}+\mathrm{H}^{\bullet}$

$\mathrm{C}_{5} \mathrm{~N}^{\bullet}+\mathrm{HC}_{2} \mathrm{H} \rightarrow \mathrm{HC}_{7} \mathrm{~N}+\mathrm{H}^{\bullet}$

Dissociation of acetylene or diacetylene to form $\mathrm{C}_{2} \mathrm{H}^{\cdot}$ or $\mathrm{C}_{4} \mathrm{H}^{\cdot}$ radicals was deemed less significant on the basis of the higher acidity of $\mathrm{HC}_{5} \mathrm{~N}$ or cyanide containing polyynes in general. Abstraction of the acetylene proton by the cyanide containing radical was ruled out on the basis

24 
of isotopic substitution experiments, although this process would not lead to formation of a longer chain. ${ }^{36}$

It is reasonable to expect that formation of $\mathrm{HC}_{9} \mathrm{~N}$ proceeds in a similar fashion starting with (1) and followed by (4) below:

$\mathrm{C}_{5} \mathrm{~N}^{\bullet}+\mathrm{HC}_{4} \mathrm{H} \rightarrow \mathrm{HC}_{9} \mathrm{~N}+\mathrm{H}^{\bullet}$

The same products may arise following the formation of ${ }^{\circ} \mathrm{C}_{4} \mathrm{H}$ :

$\mathrm{HC}_{5} \mathrm{~N}+{ }^{\circ} \mathrm{C}_{4} \mathrm{H} \rightarrow \mathrm{HC}_{9} \mathrm{~N}+\mathrm{H}^{\bullet}$

Each of these mechanisms entails the absorption of a single photon by a $\mathrm{C}_{4} \mathrm{H}_{2} / \mathrm{HC}_{5} \mathrm{~N}$ pair. The two precursors should be in close contact or, possibly, occupy neighboring matrix cages.

Just to be complete, one should also consider several other possibilities. The first is a mechanism involving the recombination of radicals:

$\mathrm{HC}_{4}{ }^{\cdot}+\mathrm{C}_{5} \mathrm{~N}^{\bullet} \rightarrow \mathrm{HC}_{9} \mathrm{~N}$

Another might be reactions within existing intermolecular complexes where the reactants are hydrogen bonded in a linear arrangement. Such complexes have been used to explain formation of $\mathrm{HC}_{5} \mathrm{~N}$ from matrix-isolated cyanoacetylene: ${ }^{35}$

$\mathrm{HC}_{3} \mathrm{~N} \cdots \mathrm{HC}_{3} \mathrm{~N}+h v \rightarrow \mathrm{HC}_{5} \mathrm{~N}+\mathrm{CN}^{\bullet}+\mathrm{H}^{\bullet}$

A scheme similar to (7) involving the intermolecular complex $\mathrm{HC}_{3} \mathrm{~N} \cdots \mathrm{HC}_{2} \mathrm{H}$ and leading to $\mathrm{HC}_{5} \mathrm{~N}$ has also been suggested for the UV-irradiated acetylene/cyanoacetylene mixture in a cryogenic matrix. $^{34}$

$\mathrm{HC}_{3} \mathrm{~N} \cdots \mathrm{HC}_{2} \mathrm{H}+h v \rightarrow \mathrm{HC}_{5} \mathrm{~N}+\mathrm{H}_{2}$

The equivalent of reactions (7) or (8) can also be envisioned to lead to formation of $\mathrm{HC}_{9} \mathrm{~N}$ :

$\mathrm{HC}_{5} \mathrm{~N} \cdots \mathrm{HC}_{5} \mathrm{~N}+h v \rightarrow \mathrm{HC}_{9} \mathrm{~N}+\mathrm{CN}^{\bullet}+\mathrm{H}^{\bullet}$ 
$\mathrm{HC}_{5} \mathrm{~N} \cdots \mathrm{HC}_{4} \mathrm{H}+h v \rightarrow \mathrm{HC}_{9} \mathrm{~N}+\mathrm{H}_{2}$

The importance of precursors bound in a complex is rather unlikely for syntheses of chains longer than $\mathrm{HC}_{5} \mathrm{~N}$. Experiments leading to formation of $\mathrm{HC}_{7} \mathrm{~N}$ showed no IR spectroscopic traces of such complexes, regardless of whether $\mathrm{HC}_{3} \mathrm{~N}+\mathrm{C}_{4} \mathrm{H}_{2}$ or $\mathrm{HC}_{5} \mathrm{~N}+\mathrm{C}_{2} \mathrm{H}_{2}$ mixtures were used. ${ }^{36}$ The same is true for the present experiment using $\mathrm{HC}_{5} \mathrm{~N}$ and $\mathrm{C}_{4} \mathrm{H}_{2}$. In addition, experiments using $\mathrm{HC}_{5} \mathrm{~N}$ as a sole precursor did not result in the appearance of $\mathrm{HC}_{9} \mathrm{~N}$ (this argument, however, should be treated with caution, given that conditions were not optimized for the detection of $\left.\mathrm{HC}_{9} \mathrm{~N}\right)$.

Reaction (6) would conclude an overall two-photon process (one photon for each radical to form). The generated radicals need to be in close physical proximity to one another for chain elongation to occur. Such a process was observed in the case of $\mathrm{NC}_{6} \mathrm{~N}$ (dicyanodiacetylene) formation from $\mathrm{HC}_{3} \mathrm{~N}$, where the production rate increased with irradiation time during the initial stages of the photolysis. This increase demonstrates that $\mathrm{C}_{3} \mathrm{~N}^{\bullet}$ radicals first needed to be created in sufficient concentration (i.e. sufficiently close to one another) before they could begin to recombine. ${ }^{35}$ Our measurements (Figure 2) show that the $\mathrm{HC}_{9} \mathrm{~N}$ production rate decreases with irradiation time suggesting that the radical recombination mechanism (6) does not occur to any great extent.

One last processes that has not yet been discussed involves precursor molecules excited to a high electronic level, rather than dissociating into a free radical. If such excitation is occurring, it could not be distinguished from a radical path with the presently reported experiments.

\section{CONCLUSIONS}

UV-driven synthesis of $\mathrm{HC}_{9} \mathrm{~N}$ in a solid rare gas matrix, via coupling of $\mathrm{HC}_{5} \mathrm{~N}$ and $\mathrm{C}_{4} \mathrm{H}_{2}$, does occur. The targeted molecule, obtained here in amounts too small for producing measurable IR absorption signals, could be detected due to its strong phosphorescence, observed here for the first time. Experimentally derived spectroscopic characteristics are in a good accordance with 26 
theoretical predictions. Phosphorescence excitation spectra gave insight to excited singlet electronic states, unattainable with standard UV absorption measurements. The forbidden $\widetilde{B}^{1} \Delta-$ $\tilde{X}^{1} \Sigma^{+}$system (rendered detectable due to coupling with a $\pi$-symmetry vibration) is well understood, while the analysis of fully allowed $\widetilde{E}^{1} \Sigma^{+}-\tilde{X}^{1} \Sigma^{+}$and $\widetilde{H}^{1} \Sigma^{+}-\tilde{X}^{1} \Sigma^{+}$transitions, entangled with forbidden transitions, requires further studies.

The described results are in agreement with previous reports on photochemical generation of similar but smaller molecules ${ }^{34-36}$ in inert cryogenic matrices and suggest the validity of the adopted approach for the synthesis and spectral studies of even longer unsaturated carbonnitrogen chains. In particular, the spectral origin of phosphorescence of a linear $\mathrm{HC}_{11} \mathrm{~N}$ can be safely predicted. The cryogenic environment proved soft enough to adapt its structure during the synthesis of an approximately $1.2 \mathrm{~nm}$ long $\mathrm{HC}_{9} \mathrm{~N}$ molecule from precursors themselves too large to occupy single trapping sites (approx. $0.4 \mathrm{~nm}$ wide) of the $f c c$-type krypton lattice. It would be interesting to go a step further and find out whether it is possible to synthesize $\mathrm{HC}_{11} \mathrm{~N}$ within a similar scheme.

Apart from $\mathrm{HC}_{9} \mathrm{~N}$, we have observed other luminescing products in the described experiments, such as $\mathrm{C}_{10} \mathrm{~N}_{2}$ (to be described separately), some of which remain unassigned. Further spectroscopic work on matrix isolated $\mathrm{HC}_{2 n+1} \mathrm{~N}$ species may lead to the detection of their isomers (in particular: isonitriles) and, as pointed out by the referee of this paper, possibly also to new insertion compounds $\mathrm{HRgC}_{2 n+1} \mathrm{~N}$, where $\mathrm{Rg}$ stands for $\mathrm{Kr}$ or Xe atoms. ${ }^{74-75}$

\section{SUPPORTING INFORMATION}

Calculated IR frequencies and intensities in accessible electronic states; visualization of vibrational modes in selected electronic states; phosphorescence excitation spectra of $\mathrm{HC}_{7} \mathrm{~N}$ and $\mathrm{HC}_{9} \mathrm{~N}$.

\section{ACKNOWLEDGMENT}

27 
This work was financially supported by the Polish National Science Centre, project no. 2011/03/B/ST4/02763, French-Polish scientific cooperation programs Partenariat HubertCurien Polonium (2012-2013) and PICS (2014-2016). U.S. is a beneficiary of the French Government scholarship Bourse Eiffel, managed by Campus France, and of the project "Scholarships for $\mathrm{PhD}$ students of Podlaskie Voivodeship". The project is co-financed by European Social Fund, Polish Government and Podlaskie Voivodeship. J.-C.G. thanks the Centre National d'Etudes Spatiales (CNES) and the French program Physique et Chimie du Milieu Interstellaire (PCMI) funded by the Conseil National de la Recherche Scientifique (CNRS) and CNES for financial support. Thanks are also due to Prof. Tomonari Wakabayashi for sharing his data on electronic absorption of $\mathrm{HC}_{9} \mathrm{~N}$.

\section{REFERENCE LIST}

(1) Turner, B. E. Detection of Interstellar Cyanoacetylene. Astrophys. J. Lett. 1971, 163, L35.

(2) Dickinson, D. F. Detection of Cyanoacetylene at 18 GHz. Astrophys. Lett. 1972, 12, 235236.

(3) McGee, R. X.; Balister, M.; Newton, L. M. Interstellar Cyanoacetylene $-\mathrm{J}=2 \rightarrow 1, \mathrm{~J}=4 \rightarrow 3$ Transitions. Mon. Not. R. Astron. Soc. 1977, 180 (4), 585-592.

(4) Gardner, F. F.; Winnewisser, G. Observations of the $\mathrm{J}=1 \rightarrow 0$ Transitions of the ${ }^{13} \mathrm{C}$ Isotopic Species of Cyanoacetylene (HCCCN) in the Direction of Sagittarius B2. Astrophys. J. 1975, 197, L73.

(5) Mauersberger, R.; Henkel, C.; Sage, L. J. Dense Gas in Nearby Galaxies. III - $\mathrm{HC}_{3} \mathrm{~N}$ as an Extragalactic Density Probe. Astron. Astrophys. 1990, 236, 63-68.

(6) Kunde, V. G.; Aikin, A. C.; Hanel, R. A.; Jennings, D. E.; Maguire, W. C.; Samuelson, R. E. $\mathrm{C}_{4} \mathrm{H}_{2}, \mathrm{HC}_{3} \mathrm{~N}$ and $\mathrm{C}_{2} \mathrm{~N}_{2}$ in Titan's Atmosphere. Nature 1981, 292 (5825), 686-688.

(7) Coustenis, A. The Atmospheric Structure of Titan from Voyager to Cassini. AGU Spring Meet. Abstr. 2007, 44. 
(8) Bockelée-Morvan, D.; Lis, D. C.; Wink, J. E.; Despois, D.; Crovisier, J.; Bachiller, R.; Benford, D. J.; Biver, N.; Colom, P.; Davies, J. K.; et al. New Molecules Found in Comet C/1995 O1 (Hale-Bopp). Investigating the Link between Cometary and Interstellar Material. Astron. Astrophys. 2000, 353, 1101-1114.

(9) Snell, R. L.; Schloerb, F. P.; Young, J. S.; Hjalmarson, A.; Friberg, P. Observations of $\mathrm{HC}_{3} \mathrm{~N}, \mathrm{HC}_{5} \mathrm{~N}$, and $\mathrm{HC}_{7} \mathrm{~N}$ in Molecular Clouds. Astrophys. J. 1981, 244, 45-53.

(10) Broten, N. W.; Oka, T.; Avery, L. W.; MacLeod, J. M.; Kroto, H. W. The Detection of $\mathrm{HC}_{9} \mathrm{~N}$ in Interstellar Space. Astrophys. J. 1978, 223, L105.

(11) Bell, M. B.; Avery, L. W.; MacLeod, J. M.; Matthews, H. E. The Excitation Temperature of $\mathrm{HC}_{9} \mathrm{~N}$ in the Circumstellar Envelope of IRC + 10216. Astrophys. J. 1992, 400, 551-555.

(12) Truong-Bach; Graham, D.; Nguyen-Q-Rieu. $\mathrm{HC}_{9} \mathrm{~N}$ from the Envelopes of IRC+10216 and CRL:2688. Astron. Astrophys. 1993, 277, 133.

(13) Bell, M. B.; Feldman, P. A.; Kwok, S.; Matthews, H. E. Detection of $\mathrm{HC}_{11} \mathrm{~N}$ in IRC + 10²16. Nature 1982, 295 (5848), 389-391.

(14) Bell, M. B.; Feldman, P. A.; Travers, M. J.; McCarthy, M. C.; Gottlieb, C. A.; Thaddeus, P. Detection of $\mathrm{HC}_{11} \mathrm{~N}$ in the Cold Dust Cloud TMC-1. Astrophys. J. Lett. 1997, 483 (1), L61.

(15) Loomis, R. A.; Shingledecker, C. N.; Langston, G.; McGuire, B. A.; Dollhopf, N. M.; Burkhardt, A. M.; Corby, J.; Booth, S. T.; Carroll, P. B.; Turner, B.; et al. Non-Detection of $\mathrm{HC}_{11} \mathrm{~N}$ towards TMC-1: Constraining the Chemistry of Large Carbon-Chain Molecules. Mon. Not. R. Astron. Soc. 2016, 463 (4), 4175-4183.

(16) Cherchneff, I.; Glassgold, A. E. The Formation of Carbon Chain Molecules in IRC +10216. Astrophys. J. Lett. 1993, 419, L41.

(17) Cherchneff, I.; Glassgold, A. E.; Mamon, G. A. The Formation of Cyanopolyyne Molecules in IRC + 10216. Astrophys. J. 1993, 410, 188-201. 
(18) Woon, D. E.; Herbst, E. Quantum Chemical Predictions of the Properties of Known and Postulated Neutral Interstellar Molecules. Astrophys. J. Suppl. Ser. 2009, 185 (2), 273.

(19) Botschwina, P.; Horn, M. Accurate Equilibrium Structure and Electric Dipole Moment of $\mathrm{HC}_{9} \mathrm{~N}$ : Predictions on the Basis of Large-Scale Coupled Cluster Calculations. J. Mol. Spectrosc. 1997, 185 (1), 191-193.

(20) Thaddeus, P.; McCarthy, M. C. Carbon Chains and Rings in the Laboratory and in Space. Spectrochim. Acta. A. Mol. Biomol. Spectrosc. 2001, 57 (4), 757-774.

(21) Boyd, R. J.; Jones, W. E.; Ling, K. W. Geometries, Energies and Polarities of Cyanopolyynes. Chem. Phys. 1981, 58 (2), 203-210.

(22) Qi, J. Y.; Chen, M. D.; Wu, W.; Zhang, Q. E.; Au, C. T. Parity Alternation of Interstellar Molecules Cyanopolyynes $\mathrm{HC}_{n} \mathrm{~N}(n=1-17)$. Chem. Phys. 2009, 364 (1-3), 31-38.

(23) Vichietti, R. M.; Haiduke, R. L. A. The Infrared Fundamental Intensities of Some Cyanopolyynes. Spectrochim. Acta. A. Mol. Biomol. Spectrosc. 2012, 90, 1-11.

(24) Vichietti, R. M.; Haiduke, R. L. A Theoretical Systematic Study of a Series of Isocyanopolyynes. Spectrochim. Acta. A. Mol. Biomol. Spectrosc. 2013, 114, 197-204.

(25) Iida, M.; Ohshima, Y.; Endo, Y. Laboratory Detection of $\mathrm{HC}_{9} \mathrm{~N}$ Using a Fourier Transform Microwave Spectrometer. Astrophys. J. 1991, 371, L45.

(26) McCarthy, M. C.; Levine, E. S.; Apponi, A. J.; Thaddeus, P. Experimental Structures of the Carbon Chains $\mathrm{HC}_{7} \mathrm{~N}, \mathrm{HC}_{9} \mathrm{~N}$, and $\mathrm{HC}_{11} \mathrm{~N}$ by Isotopic Substitution. J. Mol. Spectrosc. 2000, 203 (1), 75-81.

(27) Kroto, H. W.; Heath, J. R.; Obrien, S. C.; Curl, R. F.; Smalley, R. E. Long Carbon Chain Molecules in Circumstellar Shells. Astrophys. J. 1987, 314, 352-355.

(28) Schermann, G.; Grösser, T.; Hampel, F.; Hirsch, A. Dicyanopolyynes: A Homologuous Series of End-Capped Linear Sp Carbon. Chem. - Eur. J. 1997, 3 (7), 1105-1112. 
(29) Cataldo, F. Polyynes and Cyanopolyynes: Their Synthesis with the Carbon Arc Gives the Same Abundances Occurring in Carbon-Rich Stars. Orig. Life Evol. Biospheres 2006, 36 (56), 467-475.

(30) Cataldo, F. Monocyanopolyynes from a Carbon Arc in Ammonia: About the Relative Abundance of Polyynes Series Formed in a Carbon Arc and Those Detected in the Circumstellar Shells of AGB Stars. Int. J. Astrobiol. 2006, 5 (01), 37-45.

(31) Wakabayashi, T.; Saikawa, M.; Wada, Y.; Minematsu, T. Isotope Scrambling in the Formation of Cyanopolyynes by Laser Ablation of Carbon Particles in Liquid Acetonitrile. Carbon 2012, 50 (1), 47-56.

(32) Forte, G.; D’Urso, L.; Fazio, E.; Patanè, S.; Neri, F.; Puglisi, O.; Compagnini, G. The Effects of Liquid Environments on the Optical Properties of Linear Carbon Chains Prepared by Laser Ablation Generated Plasmas. Appl. Surf. Sci. 2013, 272, 76-81.

(33) Devienne, F. M.; Barnabé, C.; Ourisson, G. Synthesis of Further Biological Compounds in Interstellar-like Conditions. Comptes Rendus Chim. 2002, 5 (10), 651-653.

(34) Coupeaud, A.; Kołos, R.; Couturier-Tamburelli, I.; Aycard, J. P.; Piétri, N. Photochemical Synthesis of the Cyanodiacetylene $\mathrm{HC}_{5} \mathrm{~N}$ : A Cryogenic Matrix Experiment. J. Phys. Chem. A 2006, 110 (7), 2371-2377.

(35) Crépin, C.; Turowski, M.; Ceponkus, J.; Douin, S.; Boyé-Péronne, S.; Gronowski, M.; Kołos, R. UV-Induced Growth of Cyanopolyyne Chains in Cryogenic Solids. Phys. Chem. Chem. Phys. PCCP 2011, 13 (37), 16780-16785.

(36) Couturier-Tamburelli, I.; Piétri, N.; Crépin, C.; Turowski, M.; Guillemin, J.-C.; Kołos, R. Synthesis and Spectroscopy of Cyanotriacetylene $\left(\mathrm{HC}_{7} \mathrm{~N}\right)$ in Solid Argon. J. Chem. Phys. 2014, 140 (4), 044329.

(37) Turowski, M.; Crépin, C.; Douin, S.; Kołos, R. Formation and Spectroscopy of Dicyanotriacetylene $\left(\mathrm{NC}_{8} \mathrm{~N}\right)$ in Solid Kr. J. Phys. Chem. A 2014. 
(38) Trolez, Y.; Guillemin, J.-C. Synthesis and Characterization of 2,4-Pentadiynenitrile-A Key Compound in Space Science. Angew. Chem. Int. Ed. 2005, 44 (44), 7224-7226.

(39) Khlifi, M.; Paillous, P.; Delpech, C.; Nishio, M.; Bruston, P.; Raulin, F. Absolute IR Band Intensities of Diacetylene in the $250-4300 \mathrm{~cm}^{-1}$ Region: Implications for Titan's Atmosphere. J. Mol. Spectrosc. 1995, 174, 116-122.

(40) Parr, R. G.; Weitao, Y. Density-Functional Theory of Atoms and Molecules; Oxford University Press, 1989.

(41) Bauernschmitt, R.; Ahlrichs, R. Treatment of Electronic Excitations within the Adiabatic Approximation of Time Dependent Density Functional Theory. Chem. Phys. Lett. 1996, 256 (4), 454-464.

(42) Casida, M. E.; Jamorski, C.; Casida, K. C.; Salahub, D. R. Molecular Excitation Energies to High-Lying Bound States from Time-Dependent Density-Functional Response Theory: Characterization and Correction of the Time-Dependent Local Density Approximation Ionization Threshold. J. Chem. Phys. 1998, 108 (11), 4439-4449.

(43) Stratmann, R. E.; Scuseria, G. E.; Frisch, M. J. An Efficient Implementation of TimeDependent Density-Functional Theory for the Calculation of Excitation Energies of Large Molecules. J. Chem. Phys. 1998, 109 (19), 8218-8224.

(44) Perdew, J. P.; Ziesche, P.; Eschrig, H. Electronic Structure of Solids' 91; Akademie Verlag, Berlin, 1991; Vol. 11.

(45) Perdew, J. P.; Chevary, J. A.; Vosko, S. H.; Jackson, K. A.; Pederson, M. R.; Singh, D. J.; Fiolhais, C. Atoms, Molecules, Solids, and Surfaces: Applications of the Generalized Gradient Approximation for Exchange and Correlation. Phys. Rev. B 1992, 46 (11), 66716687.

(46) Perdew, J. P.; Chevary, J. A.; Vosko, S. H.; Jackson, K. A.; Pederson, M. R.; Singh, D. J.; Fiolhais, C. Erratum: Atoms, Molecules, Solids, and Surfaces: Applications of the 
Generalized Gradient Approximation for Exchange and Correlation. Phys. Rev. B 1993, 48 (7), 4978-4978.

(47) Perdew, J. P.; Burke, K.; Wang, Y. Generalized Gradient Approximation for the Exchange-Correlation Hole of a Many-Electron System. Phys. Rev. B 1996, 54 (23), $16533-$ 16539.

(48) Becke, A. D. Density $\square$ functional Thermochemistry. III. The Role of Exact Exchange. $J$. Chem. Phys. 1993, 98 (7), 5648-5652.

(49) Yanai, T.; Tew, D. P.; Handy, N. C. A New Hybrid Exchange-Correlation Functional Using the Coulomb-Attenuating Method (CAM-B3LYP). Chem. Phys. Lett. 2004, 393 (1-3), $51-57$.

(50) Dunning, T. H. J. Gaussian Basis Sets for Use in Correlated Molecular Calculations. I. The Atoms Boron through Neon and Hydrogen. J. Chem. Phys. 1989, 90 (2), 1007-1023.

(51) Kendall, R. A.; Jr, T. H. D.; Harrison, R. J. Electron Affinities of the First $\square$ row Atoms Revisited. Systematic Basis Sets and Wave Functions. J. Chem. Phys. 1992, 96 (9), 67966806.

(52) Andersson, M. P.; Uvdal, P. New Scale Factors for Harmonic Vibrational Frequencies Using the B3LYP Density Functional Method with the Triple- $\zeta$ Basis Set $6-311+\mathrm{G}(\mathrm{d}, \mathrm{p}) . J$. Phys. Chem. A 2005, 109 (12), 2937-2941.

(53) Merrick, J. P.; Moran, D.; Radom, L. An Evaluation of Harmonic Vibrational Frequency Scale Factors. J. Phys. Chem. A 2007, 111 (45), 11683-11700.

(54) Foresman, J. B.; Head-Gordon, M.; Pople, J. A.; Frisch, M. J. Toward a Systematic Molecular Orbital Theory for Excited States. J. Phys. Chem. 1992, 96 (1), 135-149.

(55) Frisch, M. J.; Trucks, G. W.; Schlegel, H. B.; Scuseria, G. E.; Robb, M. A.; Cheeseman, J. R.; Scalmani, G.; Barone, V.; Mennucci, B.; Petersson, G. A.; et al. Gaussian 09; Gaussian, Inc.: Wallingford, CT, USA, 2009. Jmol: An Open-Source Java Viewer for Chemical Structures in 3D. http://www.jmol.org/ 
(57) GABEDIT 2.4.8, Allouche, A.-R. Gabedit--a Graphical User Interface for Computational Chemistry Softwares. J. Comput. Chem. 2011, 32 (1), 174-182.

(58) Chemcraft - Graphical Program for Visualization of Quantum Chemistry Computations, http://chemcraftprog.com/; Andrienko G.A.; Chemcraft 1.8 (build 180).

(59) Dalton, a Molecular Electronic Structure Program, Release 2.0 (2005), See http://www.kjemi.uio.no/software/dalton/dalton.html; C. Angeli, K. L. Bak, V. Bakken, O. Christiansen, R. Cimiraglia, S. Coriani, P. Dahle, E. K. Dalskov, T. Enevoldsen, B. Fernandez, et al..

(60) Christiansen, O.; Koch, H.; Jørgensen, P. The Second-Order Approximate Coupled Cluster Singles and Doubles Model CC2. Chem. Phys. Lett. 1995, 243 (5), 409-418.

(61) Christiansen, O.; Koch, H.; Halkier, A.; Jørgensen, P.; Helgaker, T.; Merás, A. S. de. Large $\square$ scale Calculations of Excitation Energies in Coupled Cluster Theory: The Singlet Excited States of Benzene. J. Chem. Phys. 1996, 105 (16), 6921-6939.

(62) Hald, K.; Hättig, C.; Jørgensen, P. Triplet Excitation Energies in the Coupled Cluster Singles and Doubles Model Using an Explicit Triplet Spin Coupled Excitation Space. J. Chem. Phys. 2000, 113 (18), 7765-7772.

(63) Job, V. A.; King, G. W. The Electronic Spectrum of Cyanoacetylene: Part II. Analysis of the 2300-Å System. J. Mol. Spectrosc. 1966, 19 (1-4), 178-184.

(64) Bruston, P.; Poncet, H.; Raulin, F.; Cossart-Magos, C.; Courtin, R. UV Spectroscopy of Titan's Atmosphere, Planetary Organic Chemistry, and Prebiological Synthesis: I. Absorption Spectra of Gaseous Propynenitrile and 2-Butynenitrile in the 185- to 250-nm Region. Icarus 1989, 78 (1), 38-53.

(65) Kołos, R. Carbon-Nitrogen Chain Molecules in the Laboratory and in Interstellar Medium; Institute of Physical Chemistry of the Polish Academy of Sciences: Warsaw, 2003. 
(66) Turowski, M.; Crépin, C.; Gronowski, M.; Guillemin, J.-C.; Coupeaud, A.; CouturierTamburelli, I.; Piétri, N.; Kołos, R. Electronic Absorption and Phosphorescence of Cyanodiacetylene. J. Chem. Phys. 2010, 133 (7), 074310.

(67) Vuitton, V.; Gée, C.; Raulin, F.; Bénilan, Y.; Crépin, C.; Gazeau, M.-C. Intrinsic Lifetime of Metastable Excited $\mathrm{C}_{4} \mathrm{H}_{2}$ : Implications for the Photochemistry of $\mathrm{C}_{4} \mathrm{H}_{2}$ in Titan's Atmosphere. Planet. Space Sci. 2003, 51 (13), 847-852.

(68) Anderson, B. D.; Gordon, C. M. The Laser Synthesis of Linear Polyynes: The Particle in a Box Revisited. J. Chem. Educ. 2008, 85 (9), 1279.

(69) Maier, J. P. Electronic Spectroscopy of Carbon Chains. J. Phys. Chem. A 1998, 102 (20), $3462-3469$.

(70) Turowski, M.; Gronowski, M.; Boyé-Péronne, S.; Douin, S.; Monéron, L.; Crépin, C.; Kołos, R. The $\mathrm{C}_{3} \mathrm{~N}^{-}$Anion: First Detection of Its Electronic Luminescence in Rare Gas Solids. J. Chem. Phys. 2008, 128 (16), 164304.

(71) Turowski, M. Niskotemperaturowe Badania Fotochemii I Spektroskopii Cyjanoacetylenów O Znaczeniu Astrofizycznym. PhD Dissertation, Institute of Physical Chemistry, Polish Academy of Sciences: Warsaw, 2012.

(72) Szczepaniak, U. Spectroscopy and Photochemistry of Astrophysically Relevant Molecules of the Cyanoacetylene Family. PhD Dissertation, Institute of Physical Chemistry, Polish Academy of Sciences; Universite Paris-Sud, Universite Paris-Saclay: Warsaw, 2017.

(73) Gronowski, M. TD-DFT Benchmark: Excited States of Atoms and Atomic Ions. Comput. Theor. Chem. 2017, 1108, 50-56.

(74) Khriachtchev, L.; Lignell, A.; Tanskanen, H.; Lundell, J.; Kiljunen, H.; Räsänen, M. Insertion of Noble Gas Atoms into Cyanoacetylene: An ab Initio and Matrix Isolation Study. J. Phys. Chem. A 2006, 110, 11876-11885.

(75) Turowski, M.; Gronowski, M.; Guillemin, J.C-.; Kołos, R. Generation of H-Kr-C ${ }_{5} \mathrm{~N}$ and H-Xe-C ${ }_{5} \mathrm{~N}$ molecules. J. Mol. Struct. 2012, 1025, 140-146. 
TOC Graphic

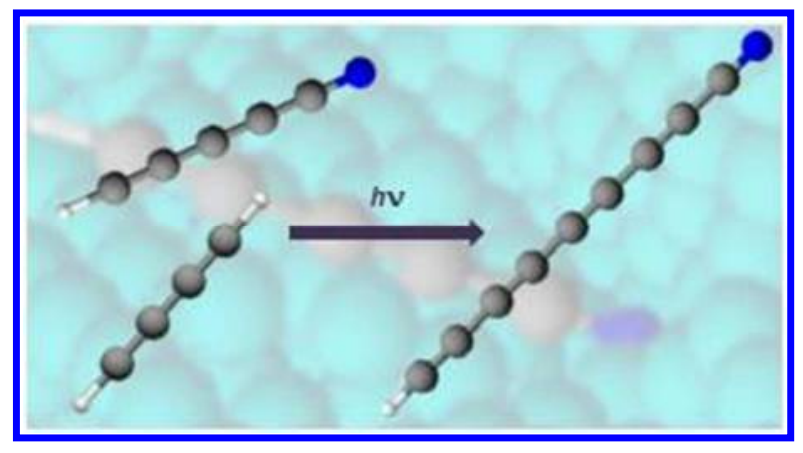

2

5

6

10

11

12 
Phosphorescence origin wavelength as a function of carbon chain length for $\mathrm{HC} 2 \mathrm{n}+1 \mathrm{~N}$ molecules. Circles mark the experimental values for $\mathrm{Kr}$ matrices ( $\mathrm{HC} 3 \mathrm{~N}$ does not phosphoresce; value observed for the isoelectronic $\mathrm{C} 3 \mathrm{~N}$ - anion70 is entered for $\mathrm{n}=1$ as an open square). Crosses correspond to CAM-B3LYP/augcc-pVTZ predictions. Experimental data for HC5N and HC7N come from Refs. 37,66.

$$
289 \times 203 \mathrm{~mm}(300 \times 300 \text { DPI })
$$

